\title{
Retrofit of heat-integrated crude oil distillation columns
}

\author{
V.M. Enríquez Gutiérrez, M. Jobson, L.M. Ochoa-Estopier, R. Smith \\ Centre for Process Integration, School of Chemical Engineering and Analytical \\ Science, The University of Manchester, United Kingdom \\ E-mail: victormanuel.enriquezgutierrez@manchester.ac.uk
}

\begin{abstract}
Engineering projects to increase the capacity of existing heat-integrated crude oil distillation columns are commonplace. Retrofit projects aim to exploit the processing capacity of existing units by changing operating parameters and/or modifying equipment. Operational modifications can be effective and usually incur little capital expenditure, but equipment changes may also be needed to achieve retrofit objectives. Existing retrofit methodologies for crude oil distillation systems mainly focus on increasing heat recovery, increasing crude oil throughput and/or increasing the yield of most valuable products by optimising column operating parameters. However, methodologies that also consider hardware modifications are lacking. The present work proposes a systematic retrofit methodology based on distillation column and heat exchanger network (HEN) simulation. Hydraulic correlations are used to consider replacing existing distillation column internals with high-capacity trays and/or structured packings. Industrially relevant case studies illustrate the benefits of the proposed methodology to analyse and assess hardware modifications for the retrofit of distillation systems when increasing capacity.
\end{abstract}

\section{Keywords}

Crude oil distillation retrofit; hydraulic analysis; distillation internals

\section{Introduction}

Crude oil distillation is an important process in petroleum refining, where whole crude is separated into products each with a narrower boiling range. An associated heat exchanger network (HEN) recovers heat from the column to pre-heat the crude oil. Together the columns and HEN comprise the crude oil distillation system. Therefore, any operating or structural change to the distillation column will have an impact on the heat recovery of the system (Gadalla et al., 2003a), making the retrofit of crude oil distillation systems a complex problem with many degrees of freedom and constraints.

Retrofit projects aim to increase the profitability of a process by maximising the use of existing equipment when production objectives change (Liu and Jobson, 2004). Objectives of retrofit projects include increasing production capacity, reducing operating cost, adding new technologies, meeting new product specifications and reducing $\mathrm{CO}_{2}$ emissions (Uerdingen et al., 2003). 
This work focuses on enabling crude oil distillation systems to accommodate more throughput. Operational modifications are preferable because they usually require little or no capital investment. Nevertheless, capacity expansion cannot always be achieved by changing operating parameters, so structural or hardware changes may also be needed. The operating and physical constraints that limit the capacity of the system are called bottlenecks.

Retrofit methodologies can be classified as sequential and simultaneous approaches. Sequential approaches debottleneck each unit separately, first the distillation column and then the HEN or vice versa, until the retrofit objective is achieved. Simultaneous approaches aim to find the optimum conditions to accommodate the new throughput while considering the heat recovery system and related trade-offs (Gadalla et al., 2013).

However, retrofit methodologies published in the open literature only account for jet flooding as a hydraulic constraint for distillation columns (related to internal vapour flows) to assess the feasibility of retrofit modifications, neglecting hydraulic constraints of the downcomer. Also, retrofit methodologies that consider replacing column internals are lacking.

This work proposes a systematic retrofit methodology for crude oil distillation systems for capacity expansion that considers structural modifications and system constraints. In the methodology, the crude oil distillation column is simulated using Aspen HYSYS and the heat exchanger network (HEN) is simulated using the model of Ochoa-Estopier et al. (2014). Hydraulic correlations are used to estimate jet and downcomer flooding, downcomer exit velocity and liquid load per weir length for conventional and high-capacity trays. Similarly, flooding and the height equivalent to a theoretical plate (HETP) for structured packings are predicted using suitable correlations. Economic correlations are applied to estimate retrofit costs.

This work applies the methodology to an industrially relevant case study, to illustrate the energy and economic trade-offs of retrofit modifications to increase the capacity of a crude oil distillation system.

\section{Literature review}

Gadalla et al. (2013) note that retrofit projects can be more cost effective than installing new designs when increasing the processing capacity of crude oil distillation systems. For this reason, retrofit methodologies that aim to increase the capacity of crude oil distillation systems are commonplace.

Gadalla et al. (2003a) propose an optimisation-based retrofit methodology that considers the interactions between the crude oil distillation column and HEN. Shortcut models for retrofit design (Gadalla et al., 2003b) are used to consider an existing crude oil distillation column, with a fixed number and distribution of stages. For the HEN, an 'area retrofit model' is proposed to relate the additional heat 
exchanger area required for retrofit to the energy consumption of the distillation column. Hydraulic constraints related to jet flooding in the distillation column are considered during the optimisation. However, downcomer flooding is not considered, neglecting the effect of liquid loads inside the distillation column. The specifications for the shortcut models used for retrofit are expressed in terms of recovery of key components, so are not straight forward to define. Constant thermal properties are assumed in the HEN retrofit model, which is known to introduce inaccuracies in the HEN modelling (Chen, 2008).

Chen (2008) overcomes some of these limitations by providing a method to estimate the key components of the product streams based on the required product specifications. The HEN retrofit model is also extended by considering temperaturedependent thermal properties and modelling of stream splitters and mixers, desalters and interconnections between HEN components (Smith et al., 2010). Jet flooding is the only hydraulic constraint considered. The downside of the shortcut methods for retrofit is that they are not computationally robust, so they require sensible initial guesses; nor do they provide the stage-by-stage information needed to perform hydraulic analysis.

Liu and Jobson (2004) propose a hydraulic performance indicator, the fractional utilization of area (FUA), to analyse the feasibility of retrofit modifications in distillation columns. Following from this work, Wei et al. (2012) propose a related hydraulic indicator, the 'maximum capacity expansion potential rate' $\left(x_{\max }\right)$, used together with the FUA to screen potential retrofit modifications in order to increase the processing capacity of distillation columns. Both hydraulic indicators are determined from results of rigorous simulations using commercial simulation software (e.g. Aspen HYSYS or Pro/lI); both parameters are only related to jet flooding.

Thernesz et al. (2010) use commercial simulation software to analyse the effect of throughput increases on a crude oil distillation system. Pro/ll is used to simulate the crude oil distillation unit. Internals vendor software, SULCOL and KG-TOWER, are used to perform hydraulic analysis of the existing column internals and to evaluate the option of replacing them with high-capacity or high-efficiency trays if the loads are exceeded. HEN design software, SUPERTARGET, is used to simulate and identify potentially useful retrofit options for the HEN. The advantages of this systematic approach is that rigorous simulation is used to simulate the distillation column, in which the models are computationally robust and provide stage-by-stage information; vendor information and suitable correlations are used to check the hydraulics of the distillation column; and the existing HEN structure and heat integration opportunities are considered. However, this approach requires significant engineering time to analyse multiple retrofit options (e.g. replacing existing trays with different high-capacity trays or structured packings), since the commercial software packages cannot work together. 
Gadalla et al. (2013) propose an optimisation-based retrofit methodology in which rigorous simulation is used to model both the distillation column and HEN. To determine the energy targets, pinch analysis is used; the maximum required diameter is used as a hydraulic constraint. Adding a preflash, prefractionator or a new pump-around are considered as retrofit options in order to increase the capacity of the system and to enhance heat recovery. However, pinch analysis is not well suited to address HEN retrofit (Ochoa-Estopier et al., 2014). Also, the required diameter evaluation only considers jet flooding.

It can be concluded that when increasing the capacity of heat-integrated crude oil distillation columns, rigorous simulation is needed, since stage-by-stage information is required to assess the hydraulic performance of distillation columns. Published retrofit methodologies only consider jet flooding as the hydraulic constraint, neglecting the effect of the downcomer hydraulics in trays; none consider replacing existing column internals with high-capacity trays or structured packings as retrofit option, except for those which use internal vendor software. Internal vendor software packages have the advantage of using suitable correlations to assess the hydraulic performance of a wide range of internals. However, they cannot work together with commercial simulation software; therefore significant engineering effort is needed to assess several retrofit options. It can also be concluded that retrofit methodologies need to consider both parts of the overall system, i.e. the distillation column and HEN.

This work proposes a retrofit methodology for increasing the capacity of heatintegrated crude oil distillation columns. The methodology aims to overcome the limitations mentioned above, to find the maximum capacity of crude oil distillation systems and to evaluate the additional heat exchanger area needed to accommodate the increased throughput. The methodology allows the engineer to analyse the effect of different column internals on the distillation column processing capacity, energy consumption and adequacy of the HEN.

\section{Retrofit methodology}

Figure 1 presents the proposed retrofit methodology for the evaluation and assessment of hardware modifications to crude oil atmospheric distillation columns when increasing capacity. The impacts on the HEN are also considered in the methodology. Using a MATLAB interface, throughput and corresponding operating parameters (e.g. pump-around duties and steam flows) are increased pro-rata and input to Aspen HYSYS v7.3 (2012), where the distillation column is simulated. The results from the simulation are used as inputs to the hydraulic correlations for the columns to check for hydraulic bottlenecks, and to a HEN simulation model to estimate the required heat transfer area and fired heating demand. Both the hydraulic correlations and HEN simulation model are coded in MATLAB. The hydraulic performance is evaluated in terms of jet flooding, liquid weir loading, downcomer exit velocity and downcomer flooding for valve trays and high-capacity 
trays, or flooding and HETP for structured packings. This methodology allows, with relatively little engineering effort, the analysis of multiple retrofit scenarios, such as finding the maximum capacity of distillation columns without the need for retrofit modifications and replacing existing internals with high-capacity trays or structured packings if the column cannot accommodate more throughput.

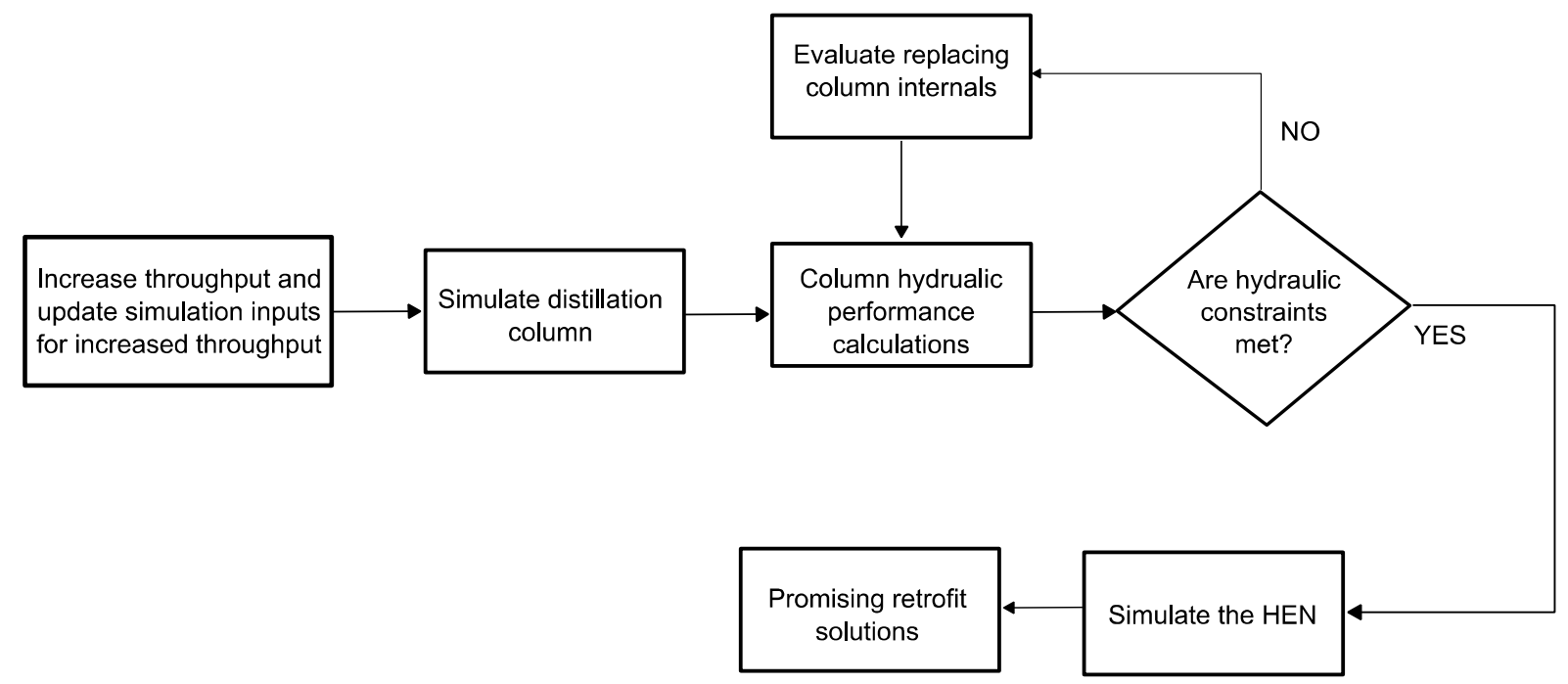

Figure 1 Proposed retrofit methodology

Figure 2 presents the key features of the atmospheric column and lists the information retrieved from HYSYS using the MATLAB code. For each stage in the column, the vapour and liquid phase flow rates and transport properties are needed for the hydraulic calculations. Inputs to the HEN simulation code are the product flowrates and temperatures, pump-around, condenser and reboiler duties and temperature drops.

Section 3.1 presents the hydraulic correlations used in this work to predict the hydraulics of distillation columns using different types of internals; the HEN simulation model is described in Section 3.2 and the economic model used to estimate the cost of retrofit is described in Section 3.3. 


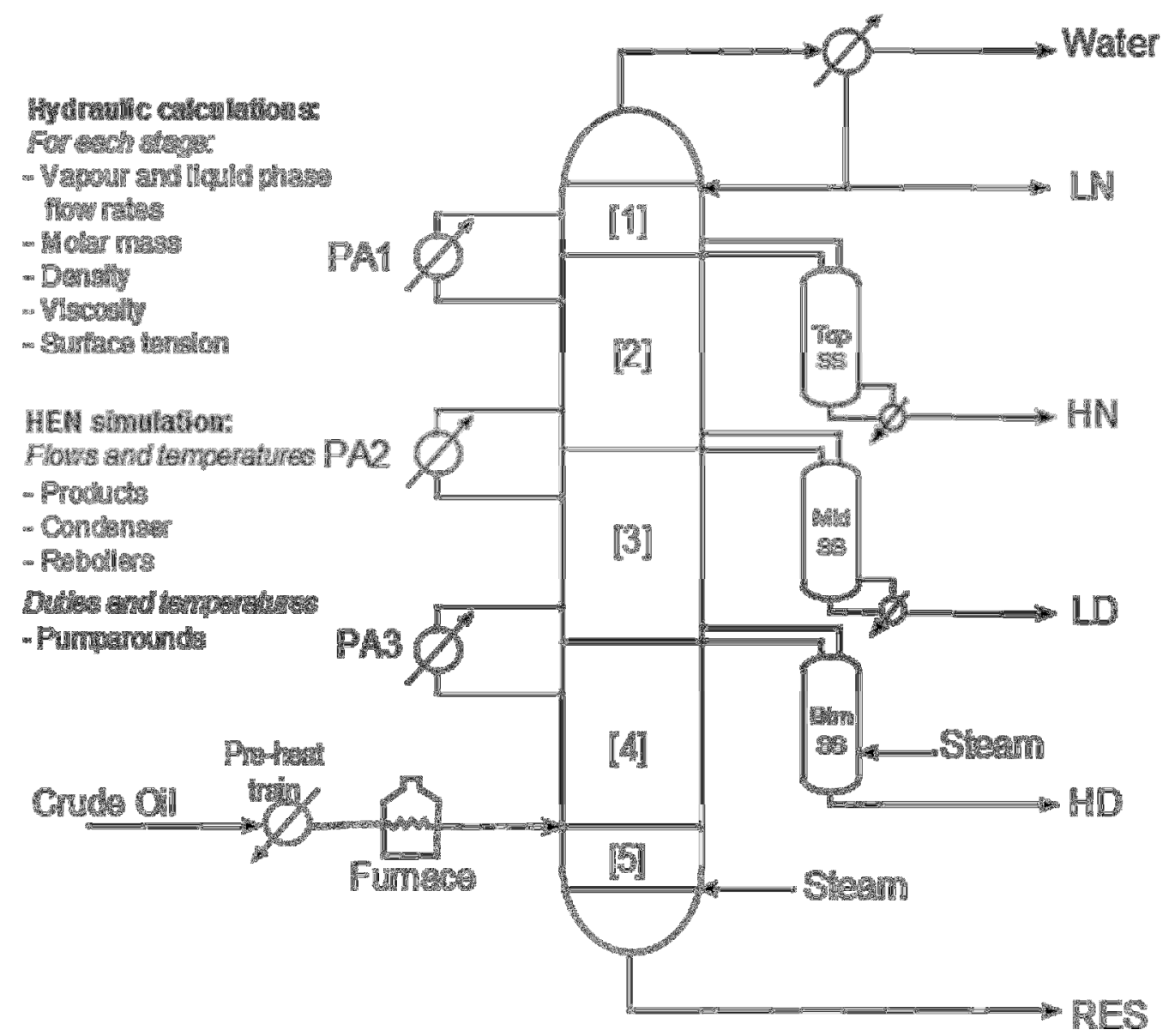

Figure 2 Distillation column information retrieved from HYSYS using MATLAB code

\subsection{Hydraulic analysis of distillation columns}

When increasing throughput for distillation columns, it is important to determine their maximum capacity in order to screen for bottlenecks (Wei et al., 2012). To determine column bottlenecks, gamma scanning of actual operation (Shahabinejad et al., 2014) or hydraulic correlations available in the open literature and simulation software (Wei et al., 2012) can be used.

This work uses hydraulic correlations to predict column bottlenecks. The hydraulic correlations that are presented in Sections 3.1.1 and 3.1.2 are also used in Aspen HYSYS v7.3 (2012) and KG-Tower v5.1 (2012). In practice, column pressure drop should be accounted as it affects the column internal flows and transport properties, thus, affecting the column hydraulics. The case study used in this work assumes constant pressure in the distillation column. However, the same correlations can still be used if the column had pressure drop since the inputs for the hydraulic correlations are retrieved from results of converged simulations, in which the column pressure drop can be accounted. Note that the methodology is not restricted to these correlations; it can also apply more accurate correlations if there are available.

Trays can operate efficiently between certain flows limits. At high vapour loads, liquid is carried over to the stage above; this phenomenon is known as jet flooding. 
Entrainment is when droplets of liquid are carried to the stage above (Stichlmair, 1998). To prevent both these phenomena, distillation columns are designed with an 'approach' to jet flooding. Weeping occurs at low vapour loads when the vapour is no longer able to prevent the liquid from leaking to the stage below (Stichlmair, 1998).

At high liquid loads, the vapour cannot disengage completely from the liquid causing vapour entrainment. This entrainment occurs when the downcomer is too small to handle the liquid load, resulting in a low downcomer residence time and/or downcomer back-up (liquid backs up to the stage from the downcomer), and it is known as downcomer flooding (Stichlmair, 1998). At low liquid loads, liquid may be almost completely vaporised, resulting in a 'dry' stage, on which counter-current vapour-liquid contact does not take place (Stichlmair, 1998). It is recommended that the downcomer flooding does not exceed 80 to $85 \%$ of the design limit (Koch-Glitsch, 2006) to prevent tower malfunction.

The literature review notes that published retrofit methodologies only consider jet flooding as a hydraulic constraint. In this work, the Glitsch correlation (Branan, 2011) is used to predict the approach to jet flooding for valve and high-capacity trays. To account for the hydraulics in the downcomer, three parameters are predicted: the liquid load per weir length and downcomer exit velocity, estimated using the same method as in KG-Tower v5.1 (2012), and downcomer flooding, using the correlation presented by Branan (2011).

This work aims to assess proposed operational and design changes against these constraints so that only feasible solutions will be selected. That is, whichever constraint is violated first becomes the controlling constraint.

Packed columns operate in countercurrent flow and use mass transfer devices with a high interfacial area to contact vapour and liquid flows (Stichlmair, 1998). These mass transfer devices, known as packings, can be divided into two groups: random packings and structured packings, where structured packings are typically much more efficient in terms of height equivalent of a theoretical plate (HETP) (Kister, 1992). Replacing conventional trays with structured packings has been used to increase the capacity of distillation columns (Kencse et al., 2007); this work considers structured packings.

To predict flooding for structured packings, the regressed model from the pressure drop correlation chart of Kister and Gill (Kister et al., 2007) presented by EnríquezGutiérrez et al. (2014) is used as flooding calculation method. The correlation used in Aspen HYSYS v7.3 (2012) is said to be based on the same pressure drop chart; no details of the correlation are presented. To estimate the HETP, a rule of thumb presented by Green and Perry (2007) is used.

\subsubsection{Hydraulic correlations for trays}


In this work, the Glitsch correlation, also known as "Equation 13" (Branan, 2011), is used to predict the 'percent flooding' for conventional trays (Equation 1). Resetarits (2014) mentions that this correlation has been used for decades with reasonable success to estimate jet flood points. In this correlation, the percent flooding is a function of the vapour load factor, $V_{\text {load }} \mathrm{m}^{3} \mathrm{~s}^{-1}$; the liquid volumetric flowrate, $V_{L}$, in $\mathrm{m}^{3} \mathrm{~s}^{-1}$; the tray flow path length, $\mathrm{T}_{\mathrm{FL}}$, in $\mathrm{m}$; the tray active area, $A_{a c}$, in $\mathrm{m}^{2}$; and the vapour capacity factor, $C F$ :

$$
\text { \%Flooding }=\frac{35.32 V_{\text {load }}+V_{L} T_{F L}}{10.76 \cdot A_{a c} \cdot C F}
$$

Distillation columns with large diameters are typically designed with an $80 \%$ approach to flooding (Branan, 2011), although some authors suggest that $85 \%$ can be considered for retrofit. This limit indicates an unacceptably high risk of jet flooding and tower malfunction (Koch-Glitsch, 2006).

The vapour load factor is the vapour rate corrected for vapour and liquid densities (Branan, 2011). It can be estimated using Equation 2, in which $V_{G}$ is the volumetric vapour load in $\mathrm{m}^{3} \mathrm{~s}^{-1}$ and $\rho_{G}$ and $\rho_{L}$ are the vapour and liquid densities in $\mathrm{kg} \mathrm{m}^{-3}$, respectively (Branan, 2011):

$$
V_{\text {load }}=V_{G} \cdot \sqrt{\frac{\rho_{G}}{\rho_{L}-\rho_{G}}}
$$

The tray flow path length is function of the tower diameter in $\mathrm{m}, D_{c}$, and the number of passes per tray, $N_{p}$ (Branan, 2011):

$$
T_{F L}=30 \frac{D_{c}}{N_{p}}
$$

The vapour capacity factor $C F$ is a function of the tray spacing in $m, T_{S}$, and the vapour density in $\mathrm{kg} \mathrm{m}^{-3}$ (Branan, 2011):

$$
C F=\left[0.58-\frac{0.084}{T_{S}}\right]-\left[\frac{2.44 \cdot T_{S} \cdot \rho_{G}-39.37 \cdot T_{S}}{1560}\right]
$$

Most retrofit methodologies neglect the effect of liquid loads on the distillation column hydraulic performance. As shown by Enríquez-Gutiérrez et al. (2014), liquid loads play an important role in the assessment of retrofit options for crude oil distillation systems. Enríquez-Gutiérrez et al. (2014) considered using the liquid load per weir length together with jet flooding to assess retrofit modifications. This work also considers the downcomer exit velocity and downcomer flooding. These parameters were observed to be sensitive to throughput increases by rating distillation columns using valve and high-capacity trays in KG-Tower v5.1 (2012) and Aspen HYSYS v7.3 (2012).

The liquid load per weir length, $L_{w}$, is function of the liquid volumetric flow rate in $\mathrm{m}^{3}$ $\mathrm{s}^{-1}$, the weir length in $\mathrm{m}, I_{w}$, and the number of passes per trays, as shown in 
Equation 5. A value between 90 and $100 \mathrm{~m}^{3} \mathrm{~m}^{-1} \mathrm{~h}^{-1}$ is used in practice as the design limit (Resetarits, 2010). If the design limit is exceeded, it is recommended to increase the number of passes to provide a better vapour-liquid contact, i.e. provide increased tray capacity (Koch-Glitsch, 2006).

$$
L_{W}=\frac{V_{L}}{l_{w} \cdot N_{p}} \cdot 3600
$$

For the downcomer exit velocity, $v_{D C e x i t}$, a limit of $0.46 \mathrm{~m} \mathrm{~s}^{-1}$ is recommended (KochGlitsch, 2006); otherwise the downcomer clearance should be adjusted. This parameter can be predicted using Equation 6, in which $H_{C l}$ is the downcomer clearance in $\mathrm{m}$ (KG-Tower v5.1, 2012).

$$
v_{\text {DCexit }}=\frac{V_{L}}{l_{w} \cdot H_{c l} \cdot N_{p}}
$$

The phenomena that cause downcomer flooding are the tray pressure drop, the liquid height on the downcomer and the frictional losses in the downcomer. These phenomena in turn are caused by high velocities in the downcomer (Kister, 1992).

To predict flooding in the downcomer, Equation 7 can be used (Branan, 2011), in which $A_{D C}$ is the downcomer area in $\mathrm{m}^{2}$ and $v_{D C \text { des }}$ is the design velocity that avoids flooding in the downcomer. The criteria used to determine the downcomer design velocity, also known as Glitsch correlations (Koch-Glitsch, 2013), are presented in Equations 8,9 and 10. The design velocity is selected from whichever is the lowest value from Equations 8, 9 and 10 (Kister, 1992).

$$
\% \text { DCflooding }=\frac{V_{L}}{A_{D C} \cdot N_{p} \cdot v_{D C d e s}}
$$

$v_{D C d e s}=0.170$

$v_{D C d e s}=0.03 \cdot \sqrt{\rho_{L}-\rho_{G}}$

$v_{D C d e s}=2.45 \cdot \sqrt{295 \cdot T_{S} \cdot\left(\rho_{L}-\rho_{G}\right)}$

Conventional trays can be modified in order to achieve more capacity and/or efficiency. These types of trays are known as high-capacity trays. Most high-capacity trays are patented designs and little information can be found about their geometry in the open literature. However, for valve trays with sloped downcomers, the same correlations (Equations 1 to 10) can be used to predict their hydraulic behaviour if the active tray area is corrected by considering the area gained by sloping the downcomer as shown in Figure 3 (KG-Tower v5.1, 2012). 

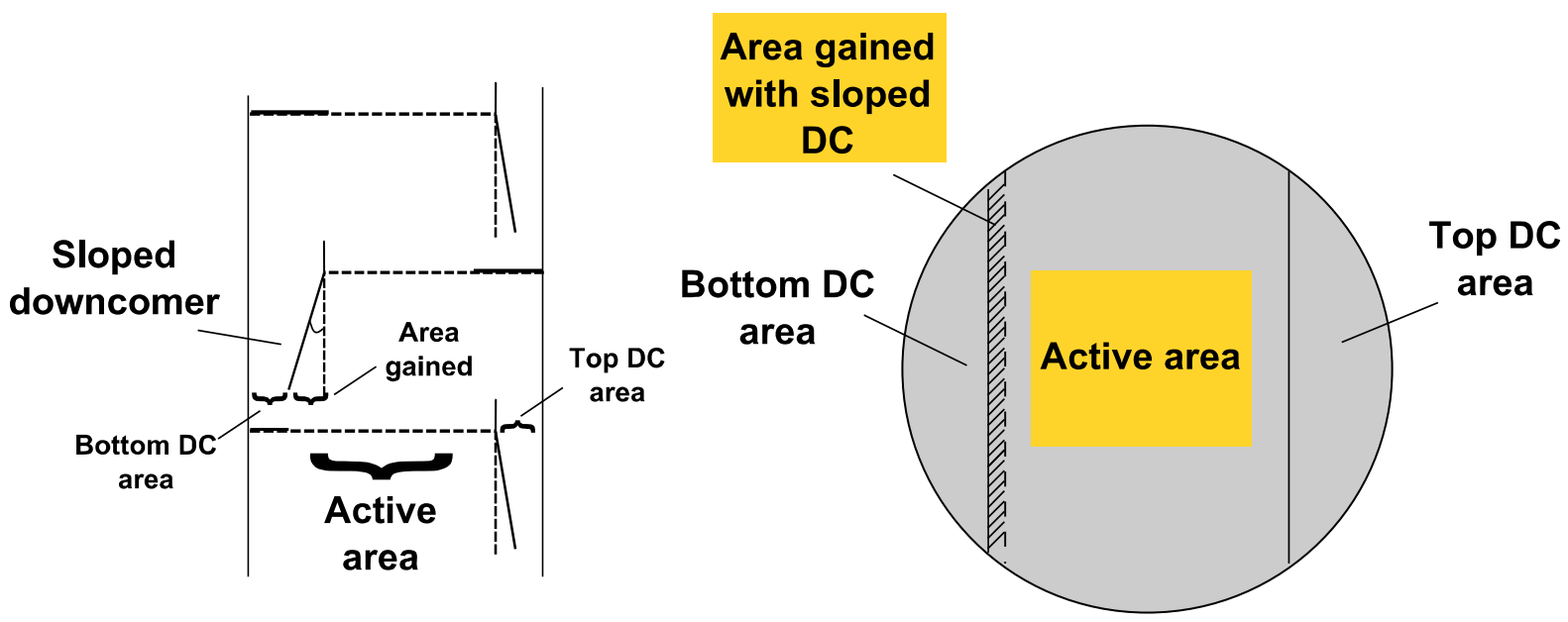

Figure 3 Increased active area when using sloped downcomers

The increased active area, when using a sloped downcomer, can be estimated (KGTower v5.1, 2012):

$A_{\text {acnew }}=A_{T}-A_{D C t o p}-A_{D C b t t m}$

where $A_{T}$ is the cross sectional area of the distillation column in $\mathrm{m}^{2}$ and $A_{D C t o p}$ and $A_{D C b t t m}$ are the top and bottom downcomer areas also in $\mathrm{m}^{2}$, respectively. The bottom downcomer area can be estimated using equation 12, in which $\theta$ is the downcomer slope angle, relative to the vertical.

$$
A_{\text {DCbttm }}=A_{\text {DCtop }} \sin \theta
$$

Equation 11 is only valid for trays with two passes. For trays with 4 passes per tray, the active area can be estimated with (KG-Tower v5.1, 2012):

$$
A_{\text {acnew }}=A_{T}-A_{D C t o p}-2 \cdot A_{D C b t t m}
$$

\subsubsection{Hydraulic correlations for packings}

The hydraulic limit for structured packings is flooding. The flood point for structured packings is defined as the pressure drop at which the liquid is no longer able to flow against the vapour, impeding countercurrent flow (Stichlmair, 1998). Packed columns are typically designed with an $80 \%$ approach to flooding. In addition, packed columns require a minimum liquid load to operate; below this limit, the packing surface is not completely wetted, reducing the mass transfer contact area and separation efficiency. For organic mixtures, it is a rule of thumb that the liquid load should be at least $2 \mathrm{~m}^{3} \mathrm{~m}^{-2} \mathrm{~h}^{-1}$ (Stichlmair, 1998).

The approach to flooding for structured packings is defined as (Kister et al., 2007):

$\%$ Flooding $=\left(C_{s b} / C_{s b, \text { flooding }}\right) * 100 \%$ 
where $C_{s b}$ is the operational capacity factor (also known as C-factor) and $C_{s b \text {,flooding is }}$ the $\mathrm{C}$-factor at flooding conditions. The $\mathrm{C}$-factor at flooding conditions for packed columns can be estimated using Equation 15, where $C P_{\text {flooding }}$ is the capacity parameter at flooding conditions, $F_{p}$ is the packing factor, an empirical factor depending on the packing size and shape, in $\mathrm{m}^{-1}$ and $\mu_{L}$ is the liquid viscosity in $\mathrm{kg}$ $\mathrm{m}^{-1} \mathrm{~s}^{-1}$ (Kister et al., 2007):

$$
C_{s b, \text { flooding }}=\frac{C P_{\text {flooding }}}{F_{p}^{0.5}\left(\mu_{L} / \rho_{L}\right)^{0.05}}
$$

Enríquez-Gutiérrez et al. (2014) proposed a regressed model from the pressure drop correlation chart for structured and random packings of Kister and Gill (1992), cited in Kister et al. (2007), to predict the capacity parameter at flooding conditions (Equation 16). In this model, the capacity parameter at flooding is a function of the flow parameter and two constants. The flow parameter $F_{V V}$ is estimated using Equation 17, where $L$ and $G$ are liquid and vapour molar flow rates, respectively, in $\mathrm{kmol} \mathrm{s}^{-1}$. The parameters $A_{\text {flooding }}$ and $B_{\text {flooding }}$ are functions of the flooding pressure drop $\Delta P_{\text {flooding }}$ in $\mathrm{Pa} \mathrm{m}^{-1}$ (Equation 18). Equations 19 and 20 provide these parameters.

$C P_{\text {flooding }}=A_{\text {flooding }} \ln \left(F_{l v}\right)+B_{\text {flooding }}$

$F_{l v}=\frac{L}{G}\left(\frac{\rho_{G}}{\rho_{L}}\right)^{0.5}$

$\Delta P_{\text {flooding }}=40.91 \cdot F_{p}^{0.7}$

$$
\begin{aligned}
A_{\text {flooding }}= & -7.31 \cdot 10^{-11} \Delta P_{\text {flooding }}^{3}+2.18 \cdot 10^{-7} \Delta P_{\text {flooding }}^{2}-2.19 \cdot 10^{-4} \Delta P_{\text {flooding }} \\
& -0.0124 \\
B_{\text {flooding }} & =1.25 \cdot 10^{-10} \Delta P_{\text {flooding }}^{3}-3.15 \cdot 10^{-7} \Delta P_{\text {flooding }}^{2}+2.62 \cdot 10^{-4} \Delta P_{\text {flooding }} \\
& +0.0826
\end{aligned}
$$

For organic mixtures this correlation is only valid for flow parameters between 0.03 to 0.3 (Kister et al., 2007). Kister et al. (2007) note that this correlation is sensitive to the packing factor; therefore it is important to obtain this parameter from a reliable source. 
In distillation columns containing trays, the compositions change from stage to stage, while in packed columns the compositions change continuously through the column. To associate this change of compositions to that of a theoretical stage, the concept of height equivalent of a theoretical plate (HETP) is used. HETP is a measure of the separation efficiency of a packed column (Smith, 2005, Ch. 9.2). To estimate a value of HETP in m, Green and Perry (2007) presented the rule of thumb shown in Equation 21, where $C_{x y}$ reflects the effect of the area of inclination and $a$ is the packing surface area in $\mathrm{m}^{2} \mathrm{~m}^{-3}$.

$$
\text { HETP }=100\left(\frac{C_{x y}}{a}\right)+0.10
$$

This correlation only applies for organic and hydrocarbon mixtures with a surface tension, $\sigma$, smaller than $25 \mathrm{mN} \mathrm{m}^{-1}$ (Green and Perry, 2007). For Y-type, S-Type or high-capacity structured packings $C_{x y}$ is equal to 1 . This correlation was obtained using experimental data; however Green and Perry (2007) mention that since the data was measured assuming perfect liquid distribution, the results obtained are slightly conservative.

Packed columns need supplementary equipment to operate properly. For example, liquid distributors are installed to ensure even liquid distribution, as poor liquid distribution impacts on the separation efficiency. Liquid collectors need to be installed in distillation columns containing side streams and pump-arounds (Stichlmair, 1998, Ch. 8.3). Smith (2005) notes that liquid collectors and distributors require 0.5 to $1 \mathrm{~m}$ of column height per bed of packing. This work assumes a value of $0.5 \mathrm{~m}$ per liquid distributor.

\subsection{Heat exchanger network (HEN) simulation model}

As mentioned in the literature review, retrofit methodologies for crude oil distillation systems should consider both the distillation column and the HEN. This work uses the HEN simulation model proposed by Ochoa-Estopier et al. (2014). The simulation model applies the principles of graph theory, as proposed by de Oliveira Filho et al. (2007), and extended by Ochoa-Estopier et al. (2013) to consider temperaturedependent heat capacities.

This simulation model calculates the utility requirements of the network and the outlet temperatures of every heat exchange unit, splitter and mixer. Equation 22 shows the feasibility solver used to ensure that the calculated temperatures do not violate stream energy balances or minimum temperature approach constraints. In Equation 22, $Q$ and $s f$ are vectors that represent the heat exchanger loads and split fractions, respectively; $T H$ and $T C$ are the inlet and outlet temperatures of an exchanger $i ; N_{H X}$ and $N_{S T}$ are the number of exchanger units and process streams, respectively; $T T_{c a l}$ and $T T$ are the calculated and specified target temperature of a stream $k$; and $\Delta T_{\min }$ is the minimum temperature approach. If any of these constraints is violated, i.e. the minimum temperature approach or the energy balance, 
the feasibility solver is called to determine new heat loads and split fractions that allow feasibility to be regained. The feasibility solver is based on that developed by Chen (2008). Though there is no unique solution (vectors $Q$ and $s f$ ), the feasibility solver does not consider the optimality of the feasible solution.

$$
\begin{aligned}
\min _{Q, s f}\|f(Q, s f)\|_{2}^{2}= & \min _{Q, s f}\left[\sum_{i=1}^{N_{H X}} \min \left(T H_{i}^{\text {out }}-T C_{i}^{\text {in }}-\Delta T_{\min }, T H_{i}^{\text {in }}-T C_{i}^{\text {out }}-\Delta T_{\min }, 0\right)^{2}+\right. \\
& \left.\sum_{k=1}^{N_{S T}}\left(T T_{c a l, k}-T T_{k}\right)^{2}\right]
\end{aligned}
$$

Ochoa-Estopier et al. (2014) uses the results generated by an artificial neural network (ANN) model of a crude oil distillation column as inputs for the HEN simulation model. This work instead generates the inputs from rigorous simulations of the distillation column using the MATLAB-HYSYS interface, allowing one to update the thermal heat capacities and outlet temperatures of the process streams for every retrofit modification.

The model of Ochoa-Estopier et al. (2014) employs the retrofit approach of Smith et al. (2010) to modify the duty of heat exchangers, add and/or delete heat exchangers, repipe and resequence heat exchangers, and add, delete or modify a bypass. In this work, the retrofit modifications allowed for the HEN are those found by the feasibility solver, i.e. vectors of heat loads and split fractions. Finding the optimum retrofit design for the HEN is out of the scope of this work. However, this methodology can be improved if an optimisation-based HEN retrofit methodology is included.

Another advantage of using this simulation model for the HEN is that heat exchangers are specified in terms of their heat capacities, allowing one to estimate the required heat exchanger additional area to accommodate the increased throughput.

\subsection{Retrofit cost estimation}

To estimate the cost of structural modifications to the distillation column when increasing capacity, simplified economic models found in the open literature are used to determine the retrofit cost of replacing existing internals to distillation columns and adding heat exchange area to the HEN. These economic models are described below. Where more accurate cost models are available, these can be applied instead.

\subsubsection{Retrofit cost of replacing distillation column internals}

Branan (2011) presents an analytical model for estimating the cost of replacing internals in a distillation column retrofit, citing Bravo (1997). In this model, the cost of 
replacing column internals is function of the hardware cost $\$$ Costhardware and installation and removal factors $F_{i}$ and $F_{R}$, respectively.

The hardware cost of high performance trays, including liquid distributors, is given in Equation 23, where $D$ is the column diameter in $\mathrm{m}$ and $N_{t}$ is the number of trays; the hardware cost of structured packing, including distributors, is given in Equation 24 where $S_{H}$ is the summation of bed heights in $\mathrm{m}$ and $N_{b}$ is the number of beds. Installation and removal factors are presented in Table 1. These factors are only valid when replacing existing trays with new ones with the same tray spacing.

$\$ \operatorname{Cost}_{H P T}=\left\lfloor 11 \cdot D^{2}\left(52 N_{t}+160\right)\right\rfloor F_{i} \cdot F_{R}$

$\$ \operatorname{Cost}_{S P}=11 \cdot D^{2}\left[260 S_{H}+160\left(2 N_{b}-1\right)\right] F_{i} \cdot F_{R}$

The cost model was first presented by Bravo (1997), so costs should be updated; this work uses the annual Chemical Engineering Plant Cost Index (CEPCI) for 1997, 386.5 (Vatavuk, 2002) and the CEPCl for December 2013, 687.9 (Chemical Engineering, 2014).

Table 1 Installation and removal factor for high-performance trays and structured packings

Installation factor

Removal factor (remove

existing trays and

replace with new

hardware)

High-performance trays

Structured packings

1.4

0.8

0.1

0.1

\subsubsection{Retrofit cost of installing additional heat exchanger area}

Chen (2008) applies the cost model presented by Smith (2005) in which it is assumed that the capital cost of a heat exchanger can be predicted using a simple relationship between the surface area $A_{H X}$ and three cost law constants a,b, and c, depending on the materials of construction, pressure rating and type of heat exchanger (Equation 25). Smith (2005) states that, even though this cost model is based on the assumption of the total heat exchanger area is divided equally between the heat exchangers, the model gives useful predictions of cost. Chen (2008) presents four cost models for: installing additional area to existing heat exchangers (Equation 26), installing new heat exchangers (Equation 27), heat exchanger repiping (Equation 28) and heat exchanger resequencing (Equation 29). The costs are given in US\$ and $A_{H X}$ in $\mathrm{m}^{2}$.

$\$ \operatorname{Cost}_{H X}=a+b \cdot\left(A_{\text {HXreq }}\right)^{c}$ 
\$Cost $_{\text {HXarea }}=1530 \cdot\left(A_{\text {HXreq }}\right)^{0.63}$

$\$$ Cost $_{H X}=13000+1530\left(A_{\text {HXreq }}\right)^{0.63}$

$\$$ Cost $_{\text {HXrepiping }}=60,000$

$\$$ Cost $_{\text {HXresequencing }}=35,000$

The capital cost predicted by this model should be also updated, since it was presented by Smith (2005). The annual CEPCI for 2005, 468.2 and the CEPCI for heat exchangers and tanks of December 2013, 621.6, (Chemical Engineering, 2014) are used in this work.

\subsection{Methodology - summary}

In summary, the proposed retrofit methodology for crude oil distillation systems for increased capacity comprises four parts. First, the distillation column is simulated using rigorous models in a commercial simulation package (HYSYS). Secondly, the hydraulic performance of different types of internals in the column is assessed using appropriate hydraulic correlations. Thirdly, the existing HEN is simulated, considering the energy balance, the HEN structure and temperature-dependent heat capacities of streams. The heat loads and stream splits are adjusted to ensure that energy balances are maintained. Finally, the costs of modifications to the column and HEN are estimated using suitable cost correlations. The methodology is coded in MATLAB to allow modelling and analysis of the whole system with a view to increasing processing capacity.

In Section 4, the proposed retrofit methodology is applied to an existing heatintegrated crude oil distillation column to show the benefits of the methodology for analysis of the operating and hydraulic performance of an existing crude oil distillation system, assessment of the impacts on both distillation column and HEN when increasing throughput, and evaluation of the feasibility and viability of hardware modifications proposed as retrofit solutions.

\section{Case studies}

The atmospheric distillation unit used as the base case is based on the case presented by Watkins (1979). It processes $100,000 \mathrm{bbl} \mathrm{d}^{-1}\left(828 \mathrm{~m}^{3} \mathrm{~h}^{-1}\right)$ of Venezuela Tía Juana Light crude oil. The unit consists of a main fractionator, three sidestrippers and three pump-arounds. Five products are produced: Light Naphtha (LN), Heavy Naphtha (HN), Light Distillate (LD), Heavy Distillate (HD) and Residue (RES). The main fractionator and HD side-stripper use steam as the stripping agent. The 
distillation column operating conditions are presented in Table 2; product specifications are summarised in Table 3 and the column structure and stage distribution are illustrated in Figure 4. For simplicity, it is assumed that there is no pressure drop in the column or heat exchangers; this assumption is not fundamental to the methodology.

The HEN structure is based on the heat exchanger network of Chen (2008), shown in Figure 5; it consists of 22 heat exchangers, $5453 \mathrm{~m}^{2}$ of heat transfer area, a fired heating demand of $62.1 \mathrm{MW}$ and it is designed with $\Delta T_{\min }$ equal to $25^{\circ} \mathrm{C}$. Process stream data and heat exchanger details are shown in Tables 4 and 5.

In the following sections, three case studies are presented. In Section 4.1, the base case, a hydraulic analysis of the base case is performed in order to determine how much throughput the distillation column can accommodate without needing retrofit solutions. In case study 1 (Section 4.2), the crude oil throughput and operating parameters are increased until the hydraulic limits are reached, identifying the column bottlenecks and the corresponding impacts on the HEN. In case study 2 (Section 4.3), hardware modifications are proposed in order to debottleneck the distillation column and the costs of replacing column internals and HEN modifications are estimated.

Table 2 Operating conditions of the crude oil distillation column (Chen, 2008, Ch. 6.1)

\begin{tabular}{|c|c|c|c|c|}
\hline Parameter & $\begin{array}{c}\text { Main } \\
\text { fractionator }\end{array}$ & $\begin{array}{l}\text { HD side- } \\
\text { stripper }\end{array}$ & $\begin{array}{l}\text { LD side- } \\
\text { stripper }\end{array}$ & $\begin{array}{l}\text { HN side- } \\
\text { stripper }\end{array}$ \\
\hline $\begin{array}{l}\text { Feed pre-heat } \\
\text { temperature } \\
\left({ }^{\circ} \mathrm{C}\right)\end{array}$ & 365 & - & - & - \\
\hline $\begin{array}{l}\text { Operating } \\
\text { pressure (bar) }\end{array}$ & 2.5 & 2.5 & 2.5 & 2.5 \\
\hline $\begin{array}{l}\text { Vaporisation } \\
\text { mechanism }\end{array}$ & Steam & Steam & Reboiler & Reboiler \\
\hline Reflux ratio & 4.17 & - & - & - \\
\hline Steam flow & & & & \\
\hline$\left(\mathrm{kmol} \cdot \mathrm{h}^{-1}\right)$ & 1200 & 250 & - & - \\
\hline $\begin{array}{l}\text { Condenser } \\
\text { duty (MW) }\end{array}$ & 47.87 & - & - & - \\
\hline
\end{tabular}




\begin{tabular}{lllll}
\hline $\begin{array}{l}\text { Reboiler duty } \\
\text { (MW) }\end{array}$ & - & - & 8.78 & 6.63 \\
\hline
\end{tabular}

Table 3 Product specifications (Chen, 2008, Ch. 6.1)

\begin{tabular}{lccc}
\hline Products & T5 $\left({ }^{\circ} \mathbf{C}\right.$, TBP $)$ & T50 $\left({ }^{\circ} \mathbf{C}\right.$, TBP $)$ & T95 $\left({ }^{\circ} \mathbf{C}\right.$, TBP $)$ \\
\hline RES & 353 & 462 & 798 \\
HD & 285 & 339 & 372 \\
LD & 190 & 248 & 317 \\
HN & 117 & 156 & 196 \\
LN & 3 & 71 & 118 \\
\hline
\end{tabular}

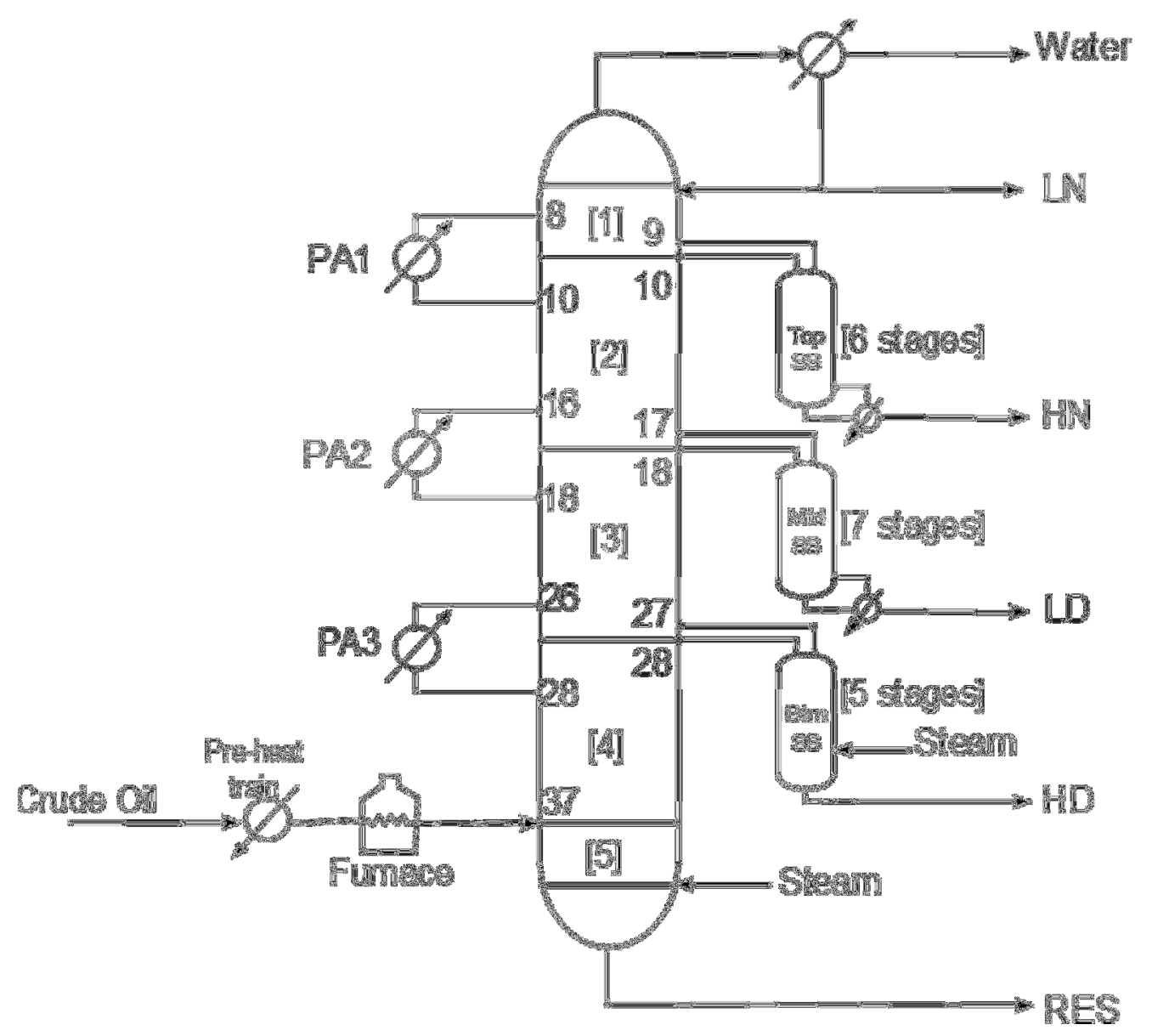

Figure 4 Stage distribution of the atmospheric distillation column (Chen, 2008, Ch. 6.1) 


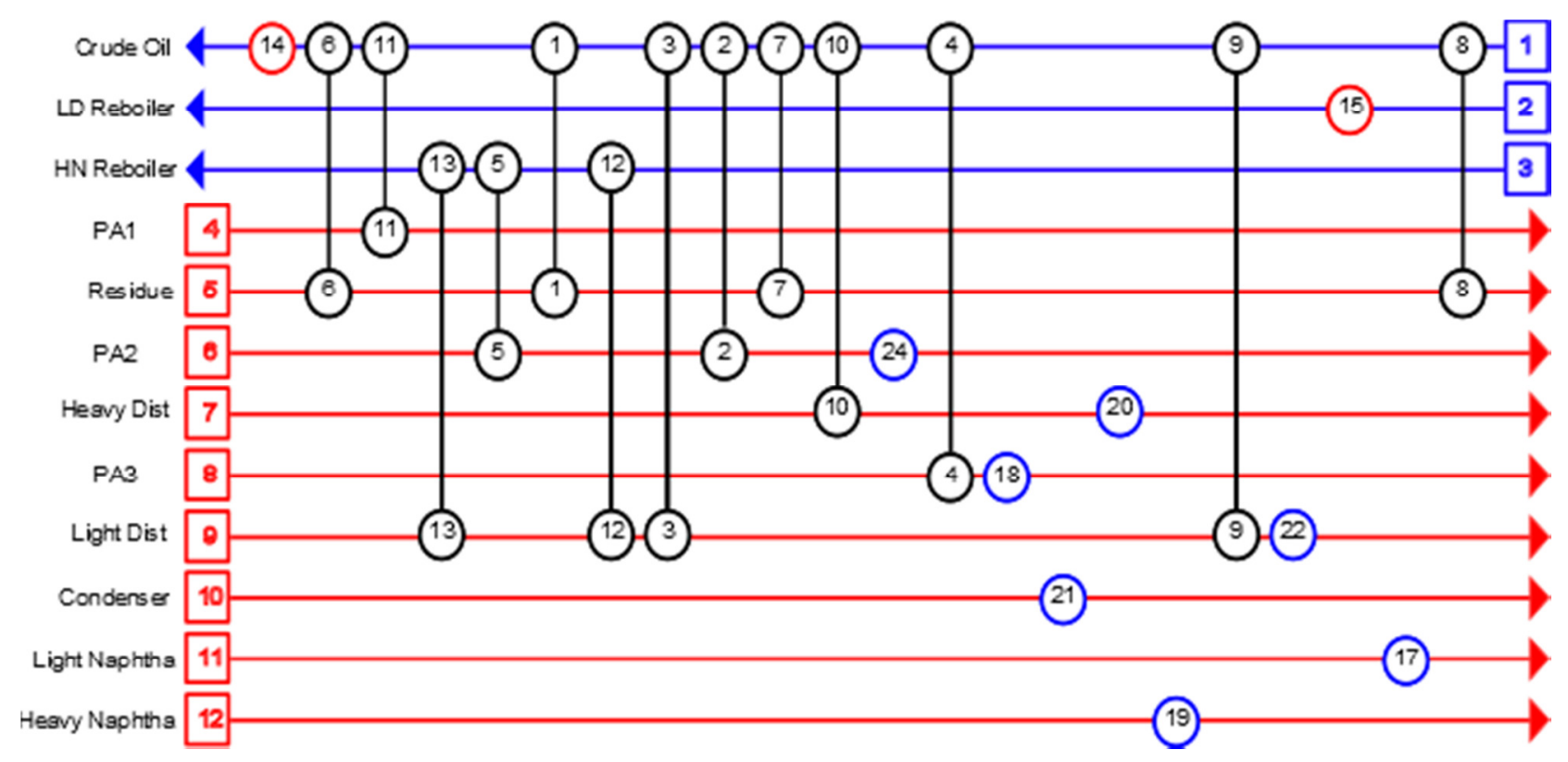

Figure 5 HEN structure (Chen, 2008, Ch. 6.1)

Table 4 Process stream data (based on Chen, 2008)

\begin{tabular}{lrrr}
\hline Stream & $\begin{array}{c}\text { Supply } \\
\text { temperature }\left({ }^{\circ} \mathbf{C}\right)\end{array}$ & $\begin{array}{c}\text { Target } \\
\text { temperature }\left({ }^{\circ} \mathbf{C}\right)\end{array}$ & $\begin{array}{c}\text { Enthalpy } \\
\text { change (MW) }\end{array}$ \\
\hline Crude oil & 25.0 & 365.0 & 143.4 \\
LD-reboiler & 262.7 & 284.3 & 6.1 \\
HN-reboiler & 172.7 & 193.8 & 3.9 \\
Cooling water (Utility) & 10.0 & 40.0 & 77.1 \\
Pump-around 1 (PA1) & 304.5 & 278.0 & 12.8 \\
Pump-around 2 (PA2) & 223.3 & 187.1 & 17.9 \\
Pump-around 3 (PA3) & 146.2 & 141.1 & 11.2 \\
Condenser & 97.2 & 76.0 & 46.7 \\
RES & 328.0 & 100.0 & 49.6 \\
HD & 262.1 & 50.0 & 5.4 \\
LD & 273.9 & 40.0 & 17.9 \\
HN & 179.3 & 40.0 & 6.5 \\
LN & 72.8 & 40.0 & 1.4 \\
Fired heating (Utility) & 1500.0 & 800.0 & 62.1 \\
\hline
\end{tabular}


Table 5 HEN details (based on Chen, 2008)

\begin{tabular}{|c|c|c|}
\hline Heat exchanger number & Installed area $\left(\mathrm{m}^{2}\right)$ & Duty (MW) \\
\hline h1 & 975 & 25.4 \\
\hline h2 & 332 & 11.5 \\
\hline h3 & 112 & 3.2 \\
\hline h4 & 196 & 5.7 \\
\hline h5 & 58 & 4.8 \\
\hline h6 & 105 & 3.3 \\
\hline h7 & 684 & 13.2 \\
\hline h8 & 312 & 10.8 \\
\hline h9 & 260 & 8.8 \\
\hline h10 & 46 & 2.1 \\
\hline h11 & 555 & 12.9 \\
\hline h12 & 22 & 1.1 \\
\hline h13 & 67 & 3.9 \\
\hline h14* & 106 & 59.6 \\
\hline h15* & 11 & 8.8 \\
\hline h17* & 59 & 8.1 \\
\hline h18* & 99 & 7.9 \\
\hline h19* & 122 & 6.5 \\
\hline h20* & 61 & 3.7 \\
\hline h21* & 1036 & 52.9 \\
\hline h22* & 179 & 6.5 \\
\hline $\mathrm{H} 24^{*}$ & 56 & 10.5 \\
\hline
\end{tabular}

*Utility heat exchanger

\subsection{Base case}

In the base case, the column internals are assumed to be valve trays with a tray spacing of $0.6 \mathrm{~m}$, active area of $91 \%$ and a downcomer clearance of $0.05 \mathrm{~m}$. As shown in Figure 4, the main fractionator is divided into five sections and it has three side strippers. The trays in sections 1 to 4 have four passes per tray and section 5 and the side-strippers have two passes per tray. Table 6 shows the tower diameters in each column section. 
Table 6 Distillation column section diameters

\begin{tabular}{lccc}
\hline & Stage number & $\begin{array}{c}\text { Passes per } \\
\text { tray }\end{array}$ & $\begin{array}{c}\text { Section diameter } \\
\left(\mathbf{m}^{\mathbf{2}}\right)\end{array}$ \\
\hline Section 1 & 1 to 9 & 4 & 7.5 \\
Section 2 & 10 to 17 & 4 & 7.5 \\
Section 3 & 18 to 27 & 4 & 8 \\
Section 4 & 28 to 36 & 4 & 8 \\
Section 5 & 37 to 41 & 2 & 5.5 \\
Top SS & 42 to 47 & 2 & 3.5 \\
Mid SS & 48 to 54 & 2 & 3.5 \\
Btm SS & 55 to 59 & 2 & 3.5 \\
\hline
\end{tabular}

The base case is simulated in Aspen HYSYS v7.3 (2012) and, using the MATLAB interface, the results from the rigorous simulation are used to estimate the jet flooding, liquid load per weir length, downcomer exit velocity and downcomer flooding using the hydraulic correlations presented in Section 3.3.1.

Figures 6 to 9 show the hydraulic results for the base case when using valve trays. As observed in the flooding profile presented in Figure 6, the column seems to be operating below the hydraulic limit, which could lead to the conclusion that the column can accommodate more throughput without needing any modifications. From the liquid load per weir length profile (Figure 7), it can be observed that the column is operating below this hydraulic limit. However, the downcomer exit velocity and flooding profiles (Figures 8 and 9) show that both parameters are close to their hydraulic limits.

From the hydraulic analysis, it can be concluded that retrofit methodologies for crude oil distillation systems that only consider jet flooding as a hydraulic constraint may lead to unfeasible retrofit designs, as some important hydraulic parameters might already be operating close to their limits.

Nevertheless, the four hydraulic parameters indicate that the column can accommodate more throughput. The next step is to determine how much throughput can be accommodated without needing to modify the distillation column, and to identify which are the limiting hydraulic parameters that bottleneck the distillation column. This information will inform the proposed retrofit modifications for the distillation column.

In case studies 1 and 2 (Sections 4.2 and 4.3), the operating conditions of the column are maintained, i.e. there is no change in the compositions and temperature profiles; the product flow rates, stripping steam flowrate and pump-around duties are all left unchanged. Section 4.2 presents the case in which the throughput of this crude oil distillation system is increased. 


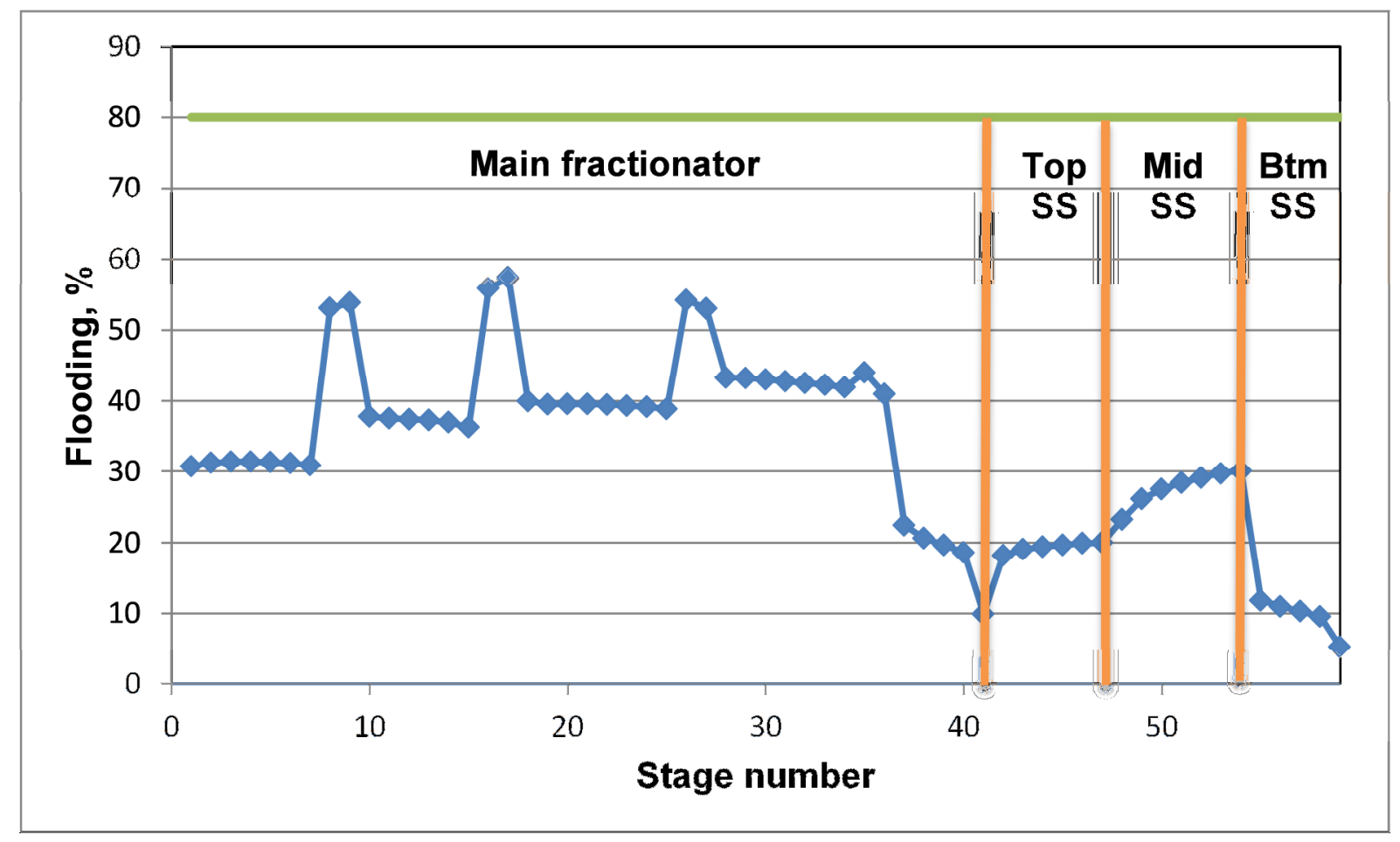

Figure 6 Percent flooding profile using standard valve trays (base case)

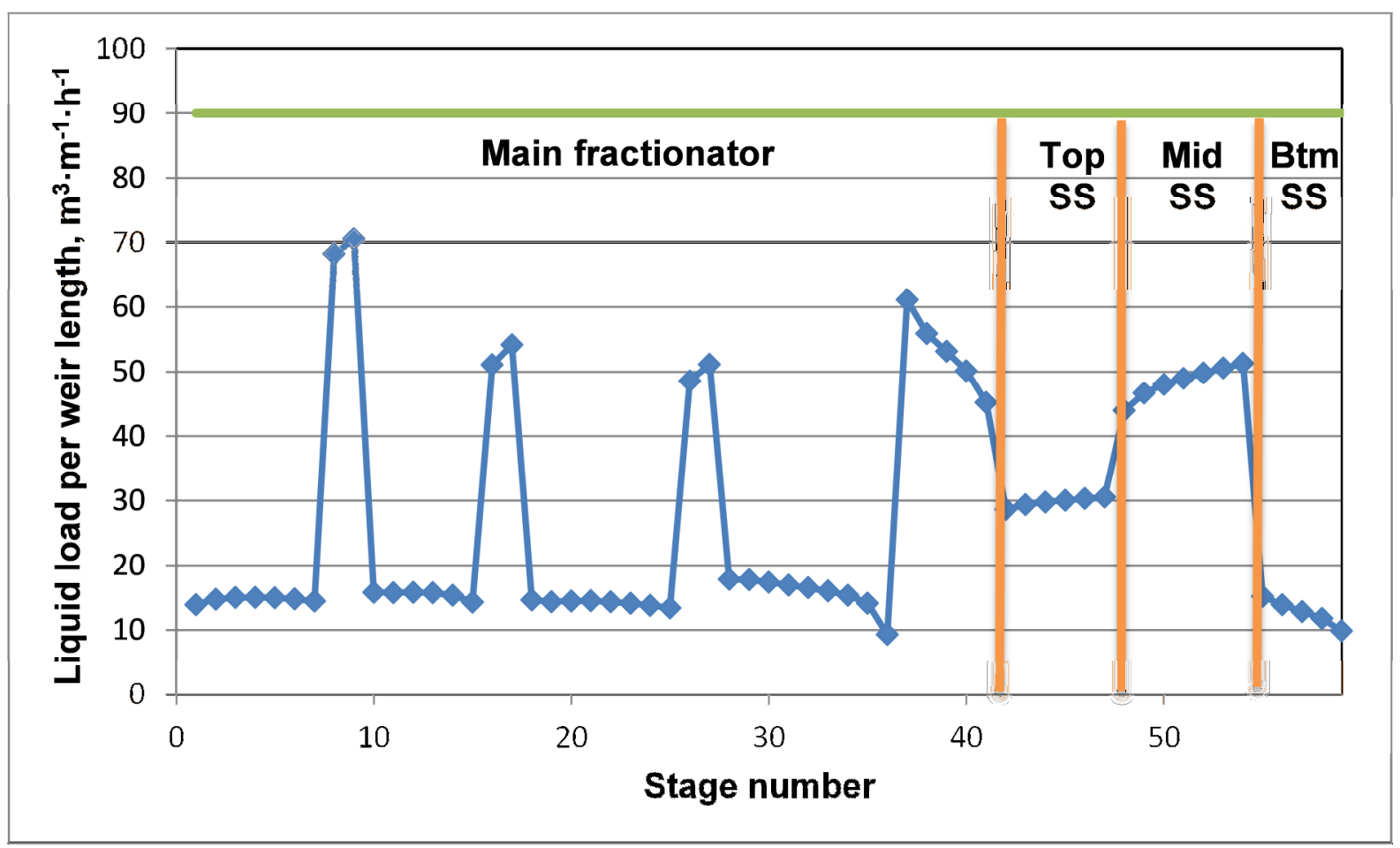

Figure 7 Liquid load per weir length profile using standard valve trays (base case) 


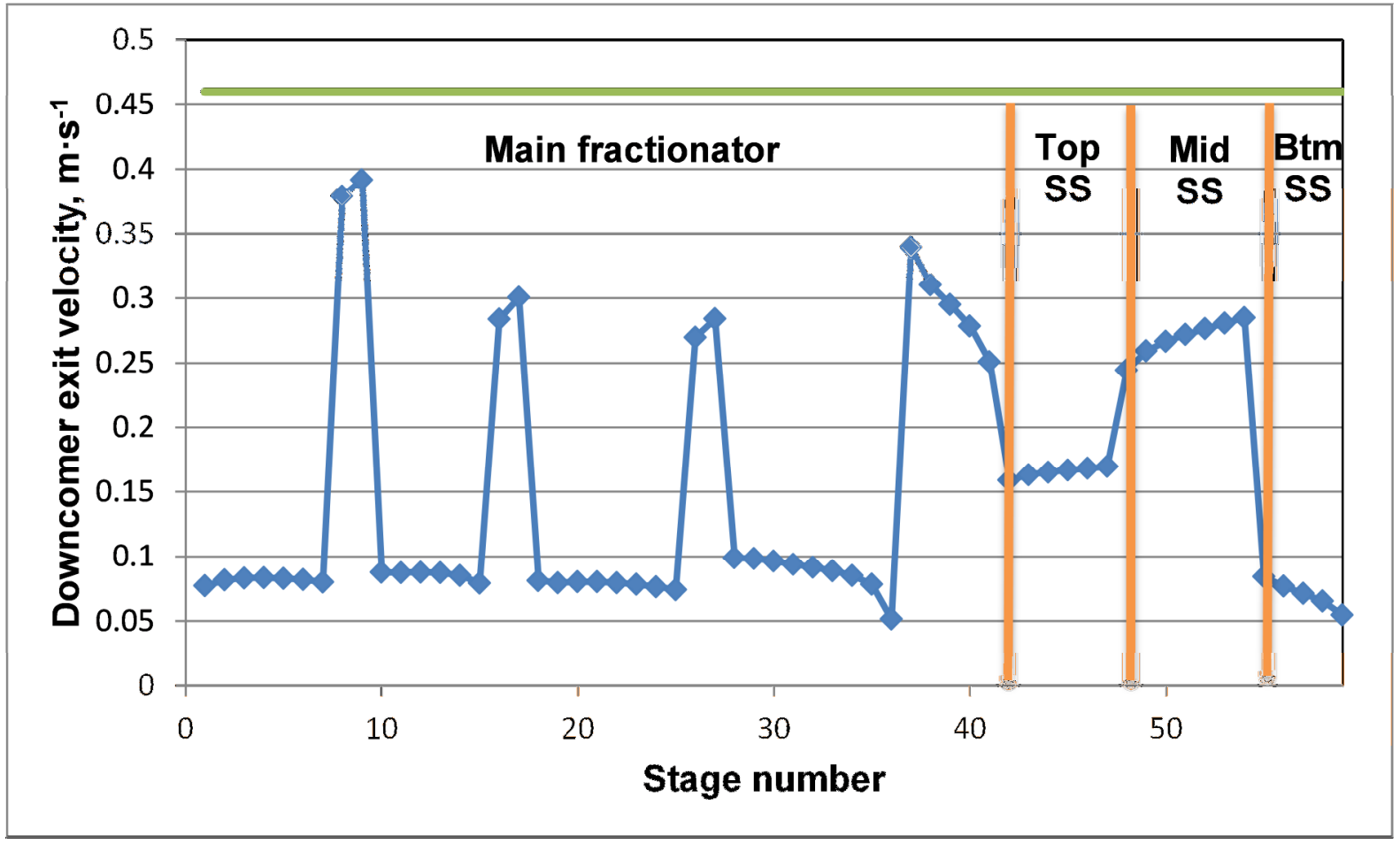

Figure 8 Downcomer exit velocity profile using standard valve trays (base case)

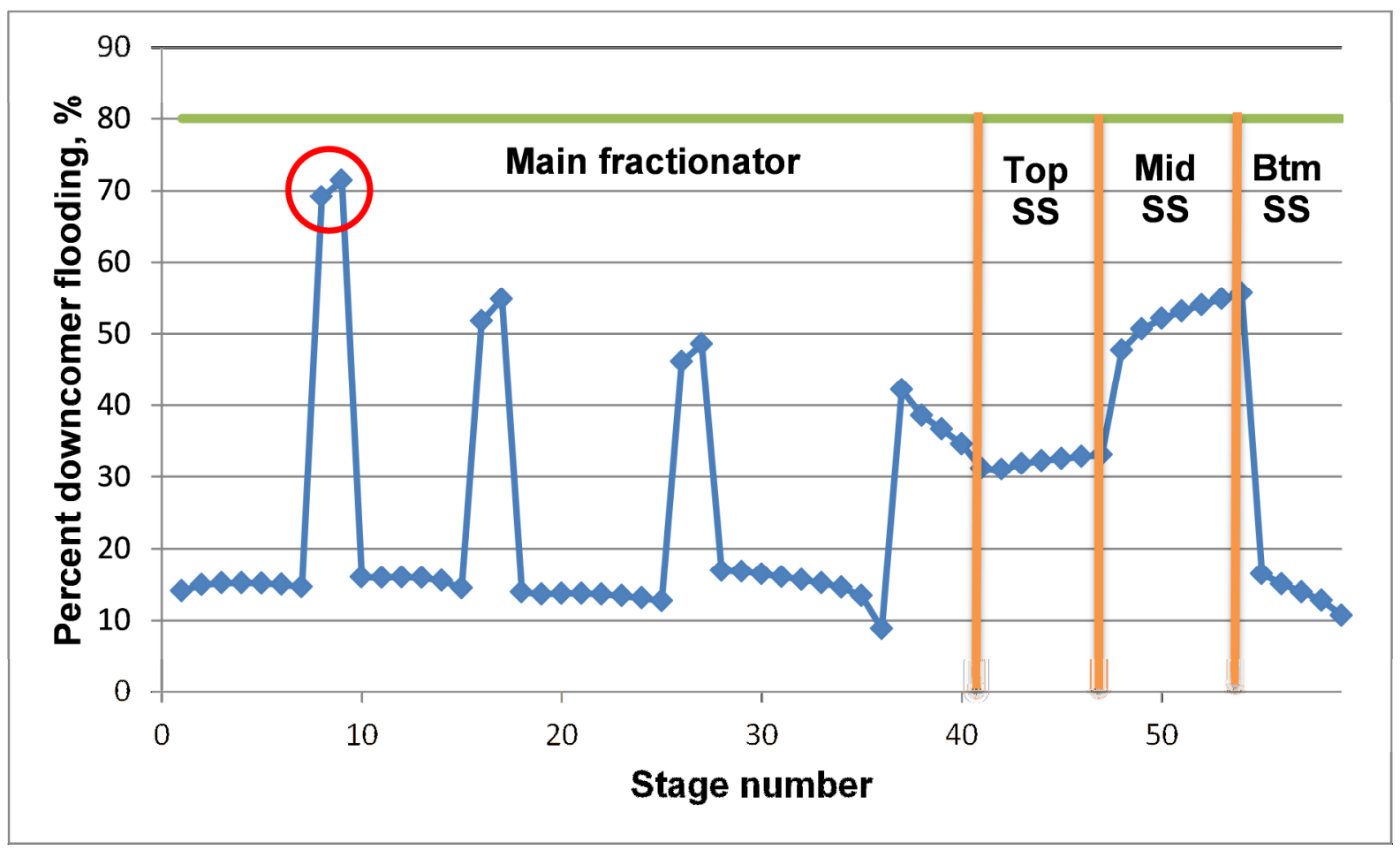

Figure 9 Downcomer flooding profile using standard valve trays (base case) 


\subsection{Case 1: Throughput increase of crude oil distillation system}

In this case study, the throughput (feed flowrate) of the base case is increased using the MATLAB-HYSYS interface by $5,10,15,20,25$ and $30 \%$. In each case the pumparounds, reboilers and condenser duties and product and stripping steam flowrates are increased pro rata; the crude oil preheat temperature and pump-arounds temperature drop are the same as in the base case. For each iteration, a hydraulic analysis of the distillation column is carried out and the HEN is simulated with a minimum temperature approach of $25{ }^{\circ} \mathrm{C}$. The aims of this case study are to determine how much additional throughput the distillation column can accommodate without requiring retrofit solutions, to identify the bottlenecks in the distillation column and to estimate how much additional heat transfer area is needed for the HEN.

From the hydraulic analysis, it can be observed that the crude oil distillation column is not limited by jet flooding when increasing throughput. Figure 10 shows that the column can accommodate $30 \%$ more throughput without exceeding the jet flooding limit. However, in Figure 11 it can be observed that with 30\% more throughput, the limit of liquid load per weir length is exceeded. Figure 12 indicates that a $20 \%$ increase in throughput will exceed the limit for the downcomer exit velocity. Figure 13 shows that the limit of downcomer flooding is exceeded if the throughput increases by $15 \%$. It is also observed from Figures 11 to 13 that Section 1 in the main fractionator is the distillation column bottleneck. Overall, it can be concluded that the column can accommodate $15 \%$ more throughput without column modifications.

Figure 14 shows the HEN modelling results in terms of requirements for additional heat transfer area and fired heating demand. It can be observed that any increase in throughput requires HEN retrofit. For every throughput increase, the feasibility solver determines the new heat loads required by the heat exchangers to meet the target temperatures of the streams. With these new heat loads, the HEN model estimates the required additional area of the HEN. The results in Figure 14 do not follow a monotonic trend, which is a consequence of the feasibility solver not seeking optimal solutions. An optimisation-based HEN retrofit methodology, e.g. the one proposed by Smith et al. (2010), is needed to identify the most economic HEN retrofit solutions. Considering HEN retrofit more systematically is a focus of future work.

Table 7 indicates which heat exchanger in the HEN requires the most additional heat exchange area, i.e. HEN bottlenecks. From Table 7, it can be observed that the heat exchangers that bottleneck the HEN are exchangers h1, h2 and h4. Of the utility exchangers, exchanger h21, the condenser, is the bottleneck. Such information could be useful for exploring HEN retrofit solutions, e.g. heat transfer enhancement of heat exchangers, splitting heat loads, etc.

Case study 1 demonstrates that the proposed retrofit methodology is useful to identify the bottlenecks of both the distillation column and HEN, and that a 
parametric analysis of crude oil distillation systems when increasing throughput provides valuable insights.

The parametric analysis reveals the maximum potential increase in throughput to the column that can be achieved without modifying the column itself. This increase, $15 \%$, would need $6 \%$ more fired heating than the base case, but the existing HEN would need significantly more heat exchanger area (around $11 \%$ ). The study has thus identified the potential of the column and highlighted the implications for HEN retrofit in a structured way.

The second case study considers hardware modifications as retrofit solutions for the distillation column. Again, finding the optimum HEN retrofit solution is not considered as it is out of scope of the present work.

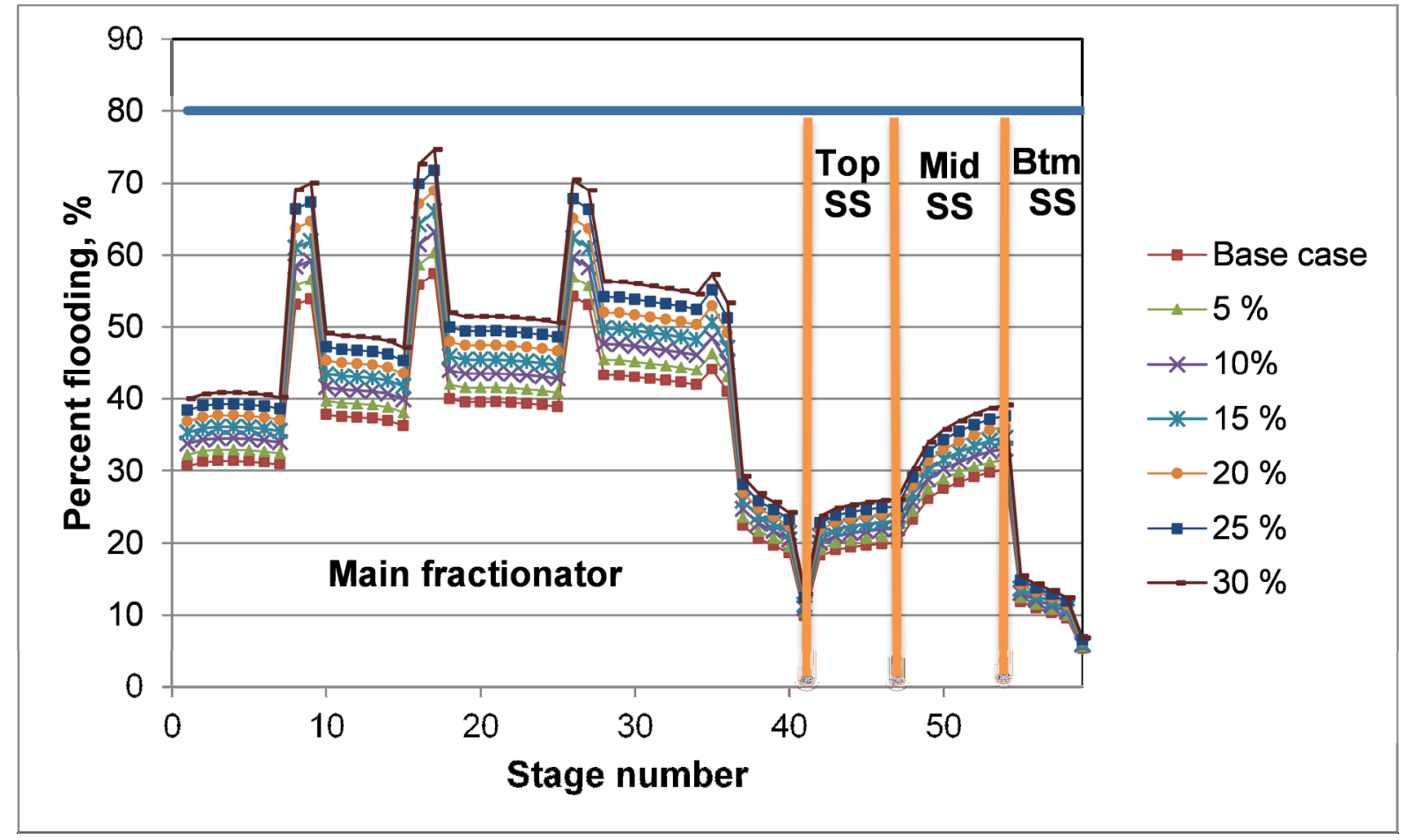

Figure 10 Percent flooding profile when increasing throughput 


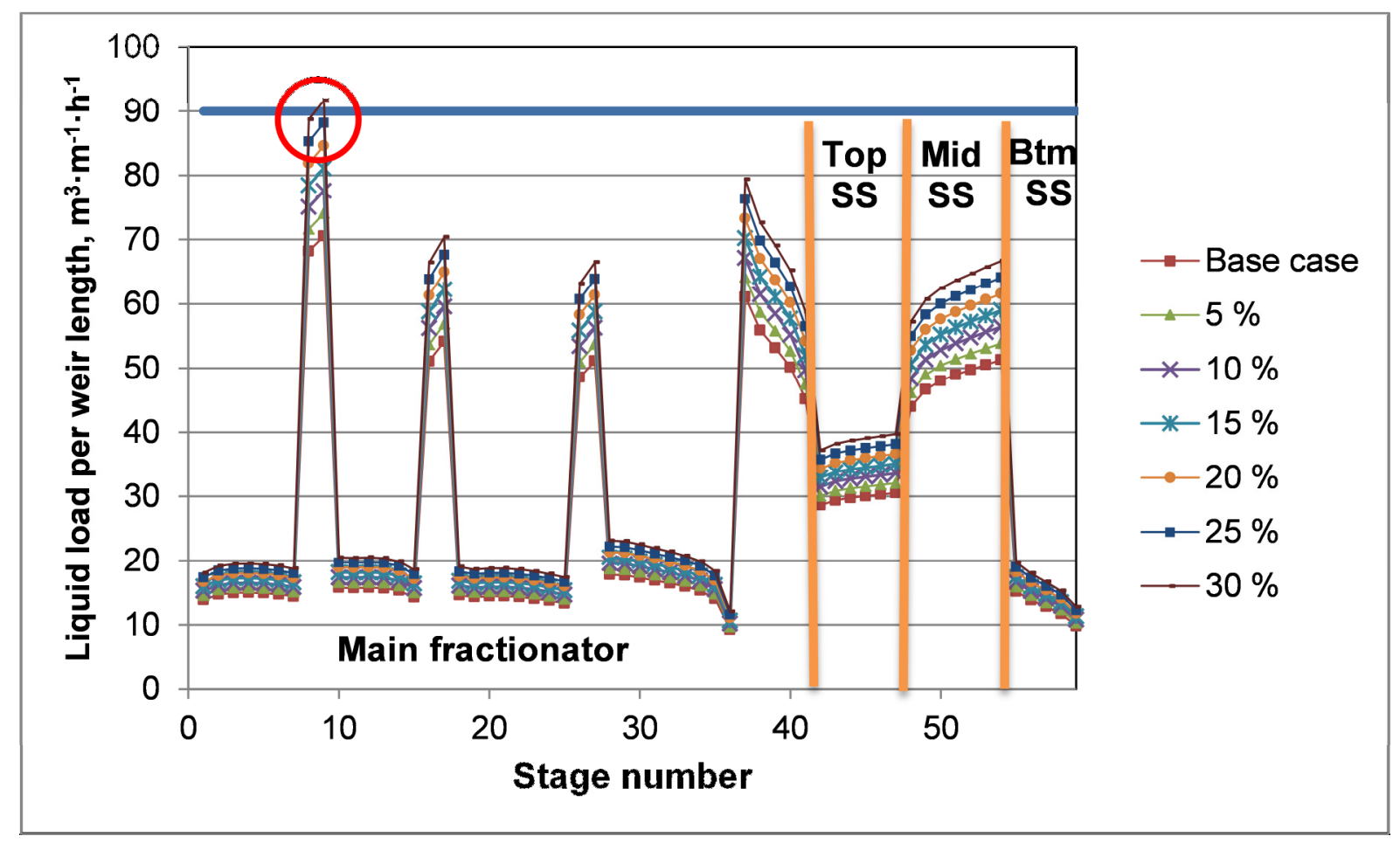

Figure 11 Liquid load per weir length profile when increasing throughput

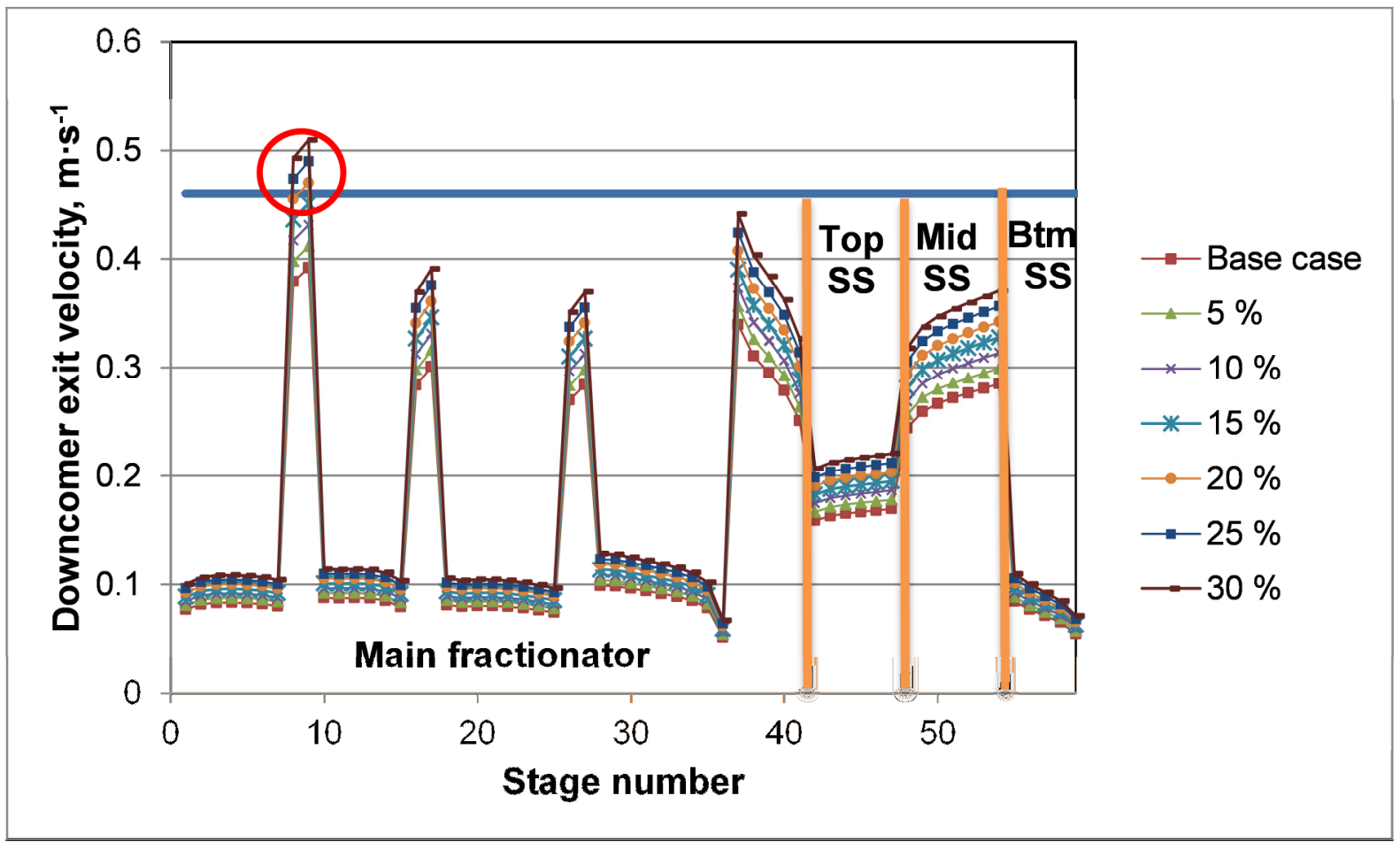

Figure 12 Downcomer exit velocity profile when increasing throughput 


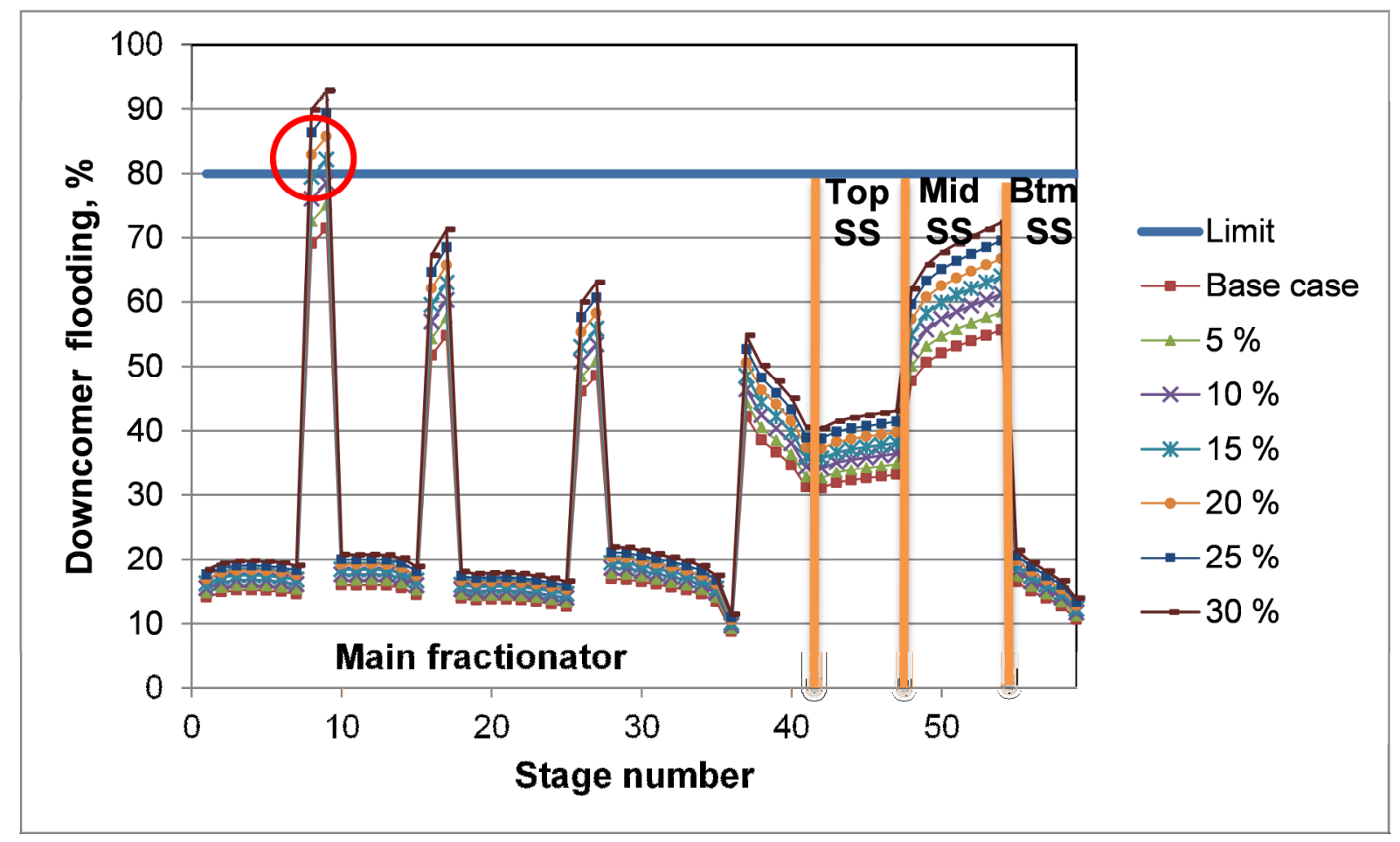

Figure 13 Downcomer flooding profile when increasing throughput

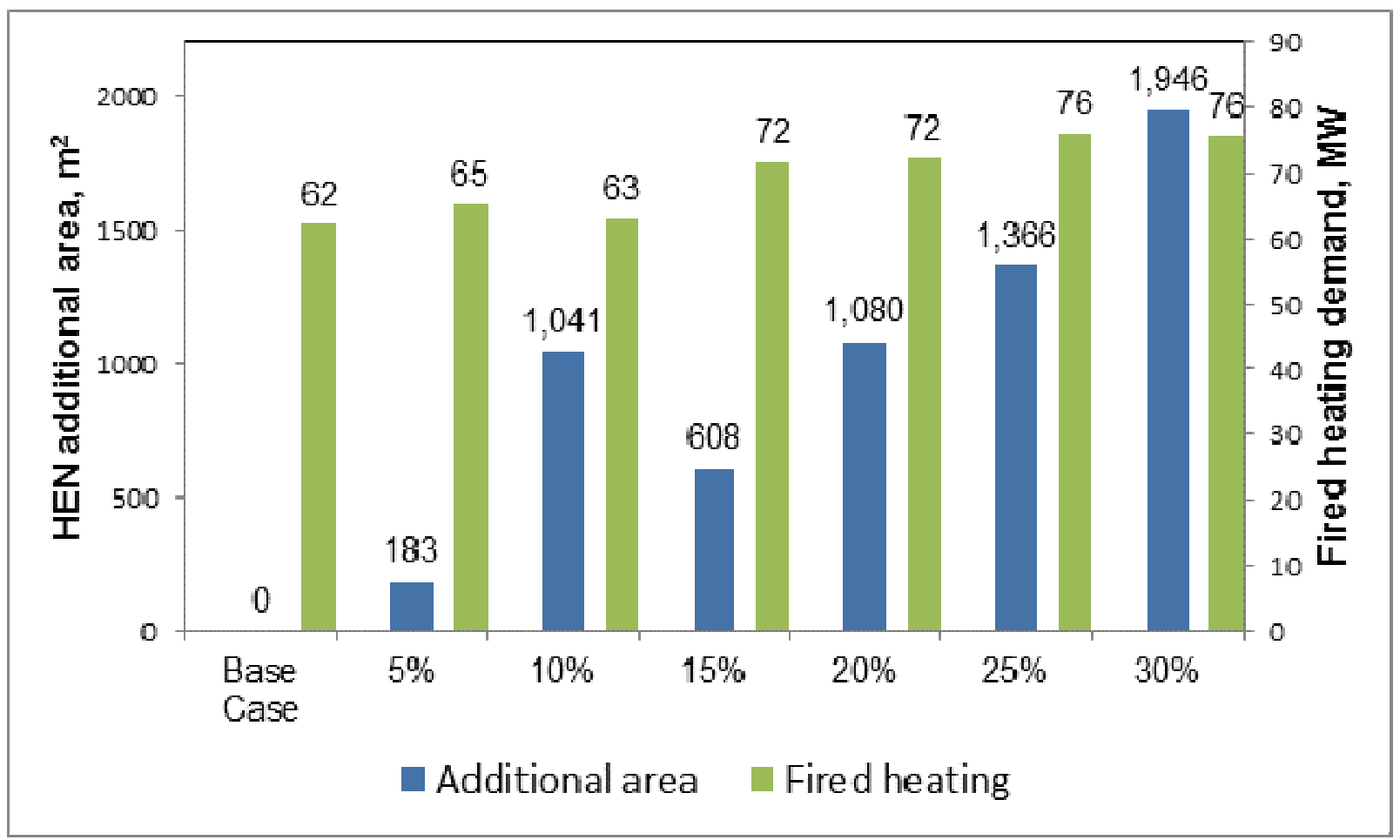

Figure 14 Impact on HEN when increasing throughput 
Table 7 HEN bottleneck when increasing throughput

\begin{tabular}{ccc}
\hline Throughput increase & Most constrained HE & $\begin{array}{c}\text { Additional area required } \\
\left(\mathbf{m}^{\mathbf{2}}\right)\end{array}$ \\
\hline $\mathbf{5 \%}$ & $\mathrm{h} 1$ & 64 \\
$\mathbf{1 0} \%$ & $\mathrm{~h} 2$ & 336 \\
$\mathbf{1 5 \%}$ & $\mathrm{h} 1$ & 124 \\
$\mathbf{2 0} \%$ & $\mathrm{~h} 2$ & 182 \\
$\mathbf{2 5} \%$ & $\mathrm{~h} 4$ & 376 \\
$\mathbf{3 0} \%$ & $\mathrm{~h} 2$ & 271 \\
\hline
\end{tabular}

\subsection{Case 2: Hardware modifications as retrofit solutions for crude oil distillation systems when increasing capacity}

The second case study aims to identify beneficial modifications to the crude oil distillation column for increased capacity. It is desired to increase the base case capacity by $30 \%$. The base case cannot accommodate $30 \%$ more capacity: the distillation column constraints relate to the downcomer exit velocity and downcomer flooding in Section 1 of the main fractionator. This case explores replacing the existing internals in Section 1 of the main fractionator with high-capacity valve trays or structured packings.

\subsubsection{Replacing existing internals with high-capacity valve trays}

Table 8 provides the parameters of a range of high-capacity trays considered as the retrofit solutions - a high-capacity tray with a $30^{\circ}$ sloped downcomer. Results of the hydraulic analysis of using high-capacity valve trays in Section 1 are shown in Figures 15 and 16.

In Figure 15, it can be observed that the liquid load per weir length is reduced as the downcomer area is increased. This is because, as the downcomer area increases, the weir length increases as well. It can also be observed from Figure 15 that jet flooding does not constrain the column in any case. Note that jet flooding increases as the downcomer area increases (i.e. as the active area is reduced).

From Figure 16, it can be concluded that only two sets of parameters for the highcapacity trays with a $30^{\circ}$ sloped downcomer satisfy both hydraulic limits when increasing throughput by $30 \%$ : high-capacity trays with an $11 \%$ downcomer area and $0.06 \mathrm{~m}$ downcomer clearance, and 12\% downcomer area and $0.06 \mathrm{~m}$ downcomer clearance. As expected, by increasing the downcomer area, the downcomer flooding is reduce; by increasing the downcomer clearance, the downcomer exit velocity is also reduced.

In summary, jet flooding increases when the tray active area is reduced. However, reducing the active area decreases the liquid load per weir length and the downcomer flooding. The solution for a high downcomer exit velocity is increasing 
the downcomer clearance. These results were expected, and shown that the proposed retrofit methodology is able to find feasible high-capacity valve trays to accommodate an increased throughput for distillation columns.

Table 8 High-capacity valve trays parameters

\begin{tabular}{ll}
\hline \multicolumn{1}{c}{ Type of trays } & \multicolumn{1}{c}{ High-capacity tray } \\
\hline Tray spacing $(\mathrm{m})$ & 0.61 \\
\% Downcomer area & $9,10,11,12,13$ \\
Downcomer clearance $(\mathrm{m})$ & $0.05,0.055,0.06$ \\
Number of flowpaths & 4 \\
Downcomer slope, degrees & 30 \\
\hline
\end{tabular}

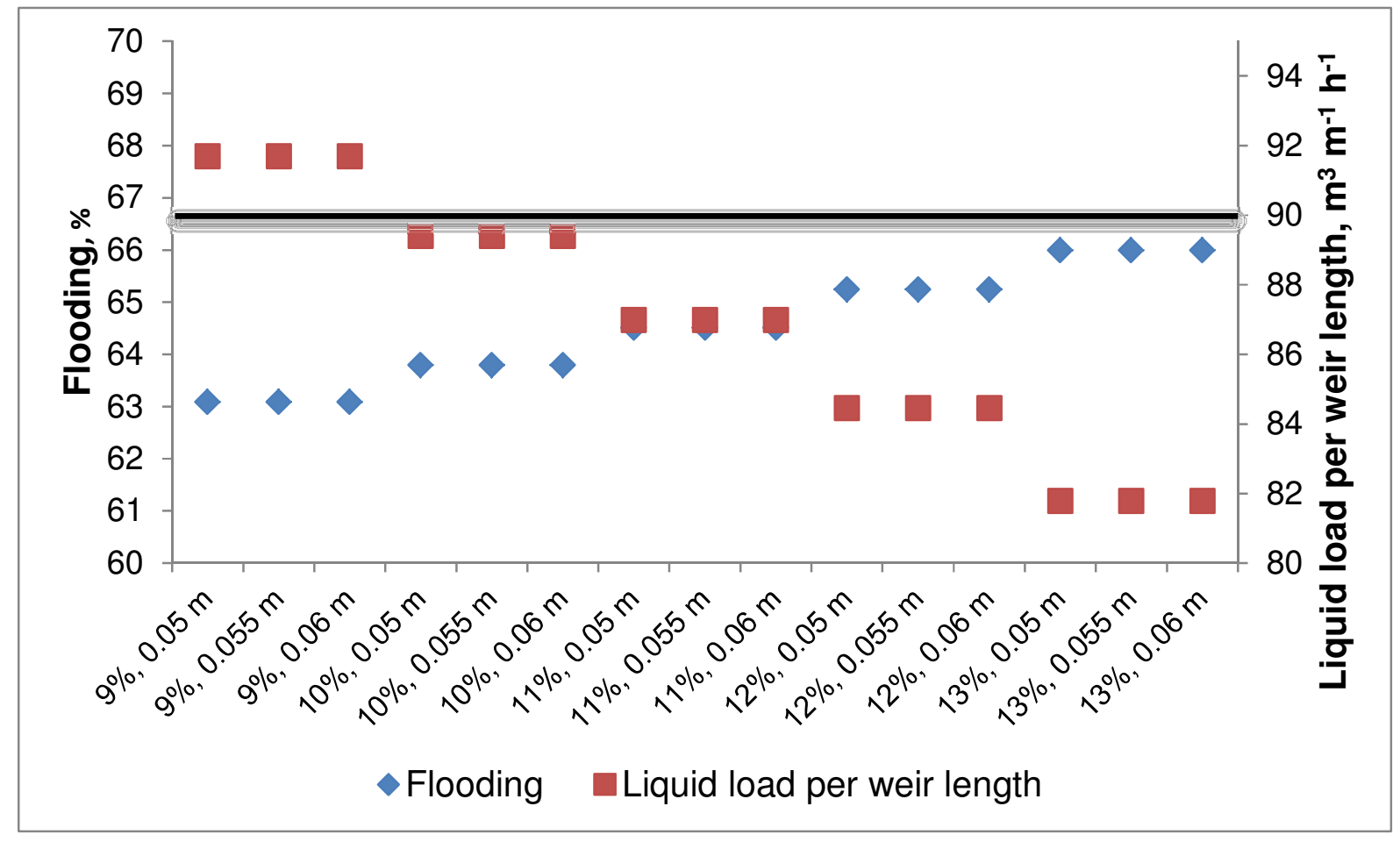

Figure 15 Maximum flooding and liquid load per weir length with high-capacity trays (\% downcomer area, downcomer clearance) when increasing throughput by $30 \%$ (section 1 , main fractionator) 


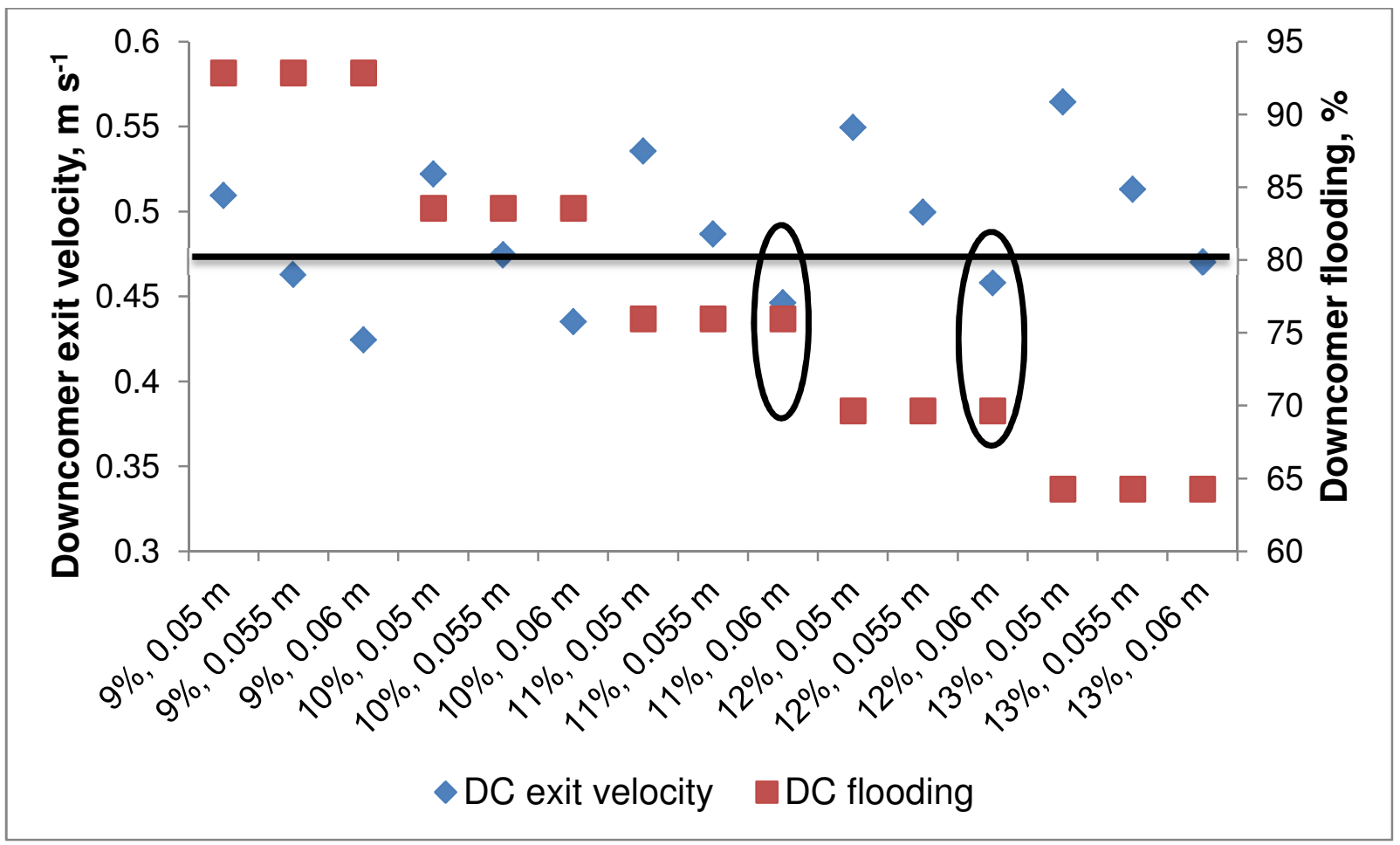

Figure 16 Maximum downcomer exit velocity and downcomer flooding with high-capacity trays (\% downcomer area, downcomer clearance) when increasing throughput by $30 \%$ (section 1, main fractionator)

\subsubsection{Replacing existing internals with structured packings}

Table 9 presents the features of the four types of structured packing considered to replace the trays in Section 1 as retrofit solutions. It can be observed from Figure 17 that the four proposed options satisfy the flooding constraint. However, as mentioned in Section 3.1.2, flooding is not the only parameter that needs to be considered. Using the HETP value of the packings, the required height to install the packings is estimated. In Table 10, the required height of the proposed structured packings, including the liquid distributors at the top of the column and the return stage of PA1 (stage 8), and the available height in the distillation column are presented. It can be observed that only structured packings Mellapak Plus $452 Y$ can be installed in the available space.

Table 9 Structured packings considered as retrofit options (Green and Perry, 2007, Ch. 14)

\begin{tabular}{lcccc}
\hline \multicolumn{1}{c}{$\begin{array}{c}\text { Type of } \\
\text { packing }\end{array}$} & Intalox 2T & Intalox 3T & $\begin{array}{c}\text { Mellapak Plus } \\
\text { 252Y }\end{array}$ & $\begin{array}{c}\text { Mellapak Plus } \\
\mathbf{4 5 2 Y}\end{array}$ \\
\hline $\begin{array}{l}\text { Surface area, } \\
\mathbf{m}^{2} \cdot \mathbf{m}^{-3}\end{array}$ & 215 & 170 & 250 & 350 \\
Void fraction & 0.99 & 0.99 & 0.98 & 0.98 \\
Packing & 56 & 43 & 39 & 69 \\
factor, $\mathbf{m}^{-1}$ & 45 & 45 & 45 & 45 \\
$\boldsymbol{\theta}$, degrees & & &
\end{tabular}




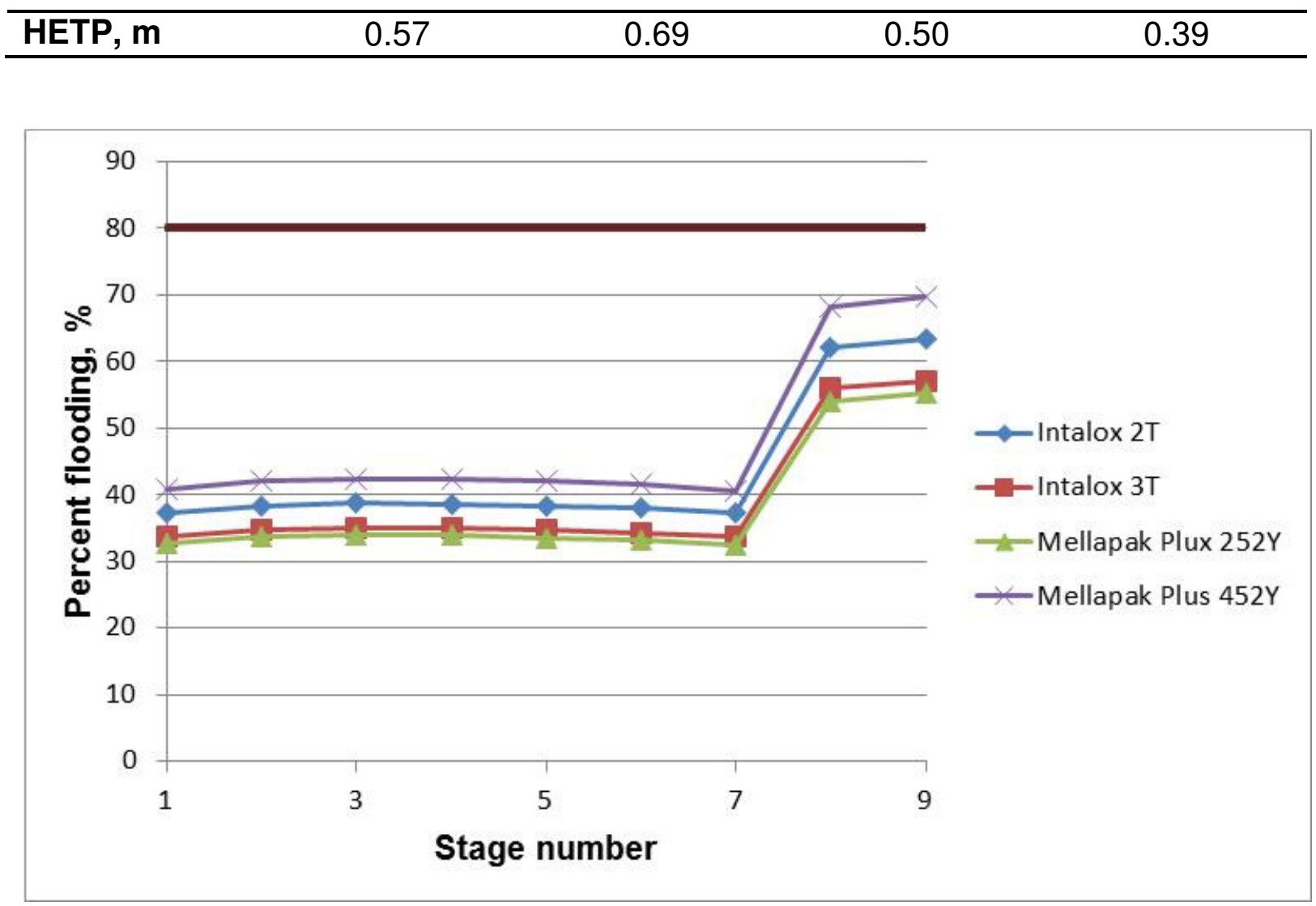

Figure 17 Percent flooding profile with structured packings when increasing throughput by $30 \%$ (section 1, main fractionator)

Table 10 Required height for replacing existing internals with structured packings

\begin{tabular}{lc}
\hline & Height, $\mathbf{~}$ \\
\hline Available height & 5.46 \\
Intalox 2T & 6.09 \\
Intalox 3T & 7.19 \\
Mellapak Plus 252Y & 5.50 \\
Mellapak Plus 452Y & 4.47 \\
\hline
\end{tabular}

\subsubsection{Summary}

In total, nineteen hardware modifications are explored to increase the capacity of the base case by $30 \%$. The engineering effort is relatively low, as the retrofit options are explored and assessed systematically, enabled by the MATLAB-HYSYS interface.

Only three of the proposed options satisfy both the hydraulic and physical constraints when increasing throughput by 30\%: replacing existing internals in Section 1 by high capacity trays with a $30^{\circ}$ sloped downcomer, 11 or $12 \%$ of downcomer area and 0.06 $\mathrm{m}$ of downcomer clearance, and Mellapak Plus 452Y structured packings.

Table 11 shows the cost estimation of the feasible retrofit options when increasing the base case capacity by $30 \%$. The associated cost of installing additional HEN 
area is also considered (see Figure 14). It can be observed that in all three retrofit scenarios the highest cost is that associated with the HEN. As mentioned before, an optimisation-based retrofit methodology can be included to reduce the HEN retrofit cost.

Table 11 Retrofit cost estimation when increasing throughput by $30 \%$ and replacing existing internals in section 1

\begin{tabular}{lccc}
\hline \multicolumn{1}{c}{ Retrofit Cost } & $\mathbf{1 1} \%, \mathbf{0 . 0 6} \mathbf{~ m}^{\star}$ & $\mathbf{1 2} \%, \mathbf{0 . 0 6} \mathbf{~ m}^{*}$ & $\begin{array}{c}\text { Mellapak Plus } \\
\mathbf{4 5 2 Y}\end{array}$ \\
\hline $\begin{array}{l}\text { Cost of replacing } \\
\text { existing hardware }\end{array}$ & $\$ 96,823$ & $\$ 96,823$ & $\$ 116,520$ \\
$\begin{array}{l}\text { Cost HEN } \\
\text { additional area }\end{array}$ & $\$ 239,809$ & $\$ 239,809$ & $\$ 239,809$ \\
Total & $\$ 336,632$ & $\$ 336,632$ & $\$ 356,329$ \\
\hline
\end{tabular}

*\% downcomer area, downcomer clearance

\subsection{Case study conclusions}

In this section, the proposed retrofit methodology was used to explore increasing the throughput of an existing heat-integrated crude oil distillation column. The column used as base case, consists of a main fractionator (steam stripped), three side strippers (one steam stripped, two reboiled), three pump-arounds and a condenser. The associated HEN is based on the one presented by Chen (2008), it consists of 22 heat exchangers with $5453 \mathrm{~m}^{2}$ of heat transfer area and demands $62.1 \mathrm{MW}$ of fired heating. For the base case (Section 4.1), the column internals were assumed to be valve trays.

In Section 4.1, a hydraulic analysis of the base case was performed. Jet flooding, liquid load per weir length, downcomer exit velocity and downcomer flooding profiles were predicted using the hydraulic correlations presented in Section 3.1. It was shown that the column was not constrained by any of these hydraulic parameters; thus the distillation column could accommodate more throughput without needing retrofit solutions to the column.

The next step was to find how much throughput could be accommodated without needing retrofit solutions to the distillation column. In case study 2 (Section 4.2), the proposed retrofit methodology was used to perform a parametric analysis of the heat-integrated crude oil distillation column for throughput increases of 5,10,15,25 and $30 \%$. The hydraulic analysis of the distillation column revealed that the column could accommodate $15 \%$ more throughput without needing retrofit solutions. From the hydraulic analysis, it was also learned that the Section 1 of the main fractionator was the column bottleneck, and that the limiting hydraulic parameters were the downcomer exit velocity and downcomer flooding. Results from the HEN, showed that around $11 \%$ more heat exchanger area and $6 \%$ more fired heating were needed to accommodate $15 \%$ more throughput. It was noted that the HEN results did not follow a monotonic trend (see Figure 14), as result of the feasibility solver not 
seeking an optimum solution for the heat loads and split fractions that regained the feasibility of the system. Therefore, it was concluded that the proposed methodology can be improved if an optimisation-based HEN retrofit methodology (e.g. the retrofit methodology proposed by Smith et al., 2010) is included.

In case study 3 (Section 4.3), it was desired to increase the throughput of the base case by $30 \%$. As learned from case study 2 , the column could not accommodate more than $15 \%$ without needing retrofit solutions. The column bottlenecks in Section 1 related to the downcomer exit velocity and downcomer flooding. High-capacity trays with $30^{\circ}$ sloped downcomer and four structured packings were proposed to replace the existing internals in Section 1 of the main fractionator. First, feasible high-capacity trays were found using the proposed retrofit methodology. Then, the structured packings were checked in order to find which could be installed in the available space. Results showed that high-capacity trays with $11 \%$ and $12 \%$ downcomer area and $0.06 \mathrm{~m}$ of downcomer clearance could accommodate the increased throughput, and Mellapak Plus $452 Y$ was the only structured packing that could fit in the available space. The economic analysis of the system revealed that the highest cost was that associated with HEN retrofit; it was concluded that an optimisation-based HEN retrofit methodology could be useful to improve these results and should be a focus of future work.

The case studies showed that the proposed methodology is useful to analyse the hydraulic performance of the base case, to analyse the impacts on both distillation column and HEN when increasing capacity and to identify system bottlenecks. It was also shown that the proposed retrofit methodology is useful to assess proposed equipment hardware modifications. However, it is always recommended to contact internals vendors in order to get more accurate estimations, given that the hydraulic and cost correlations used in this work are very general. Another limitation of the methodology is that practical considerations, such as downtime and lay-out of the plant are not considered.

\section{Conclusions}

The literature review argued that most retrofit methodologies only consider jet flooding as the hydraulic limit of distillation columns, and none systematically consider replacing existing internals with high-capacity trays or structured packings. It was noted that for crude oil distillation systems, both the distillation column and the HEN need to be considered, and that using commercial design software to simulate the distillation column and HEN and estimate the hydraulics of the distillation column requires significant engineering effort.

This work proposes a systematic retrofit methodology for the capacity enhancement of crude oil distillation systems focusing on retrofit of the column. Case studies show the importance of considering a wide range of hydraulic parameters in order to 
assess bottlenecks and proposed retrofit modifications: jet flooding, liquid load per weir length, downcomer exit velocity and downcomer flooding.

The proposed retrofit methodology can be improved if more accurate hydraulic and cost correlations are used and if other retrofit options, apart from equipment modifications, are considered (e.g. modifying operating conditions, adding separation equipment). A suitable optimisation-based HEN retrofit methodology is also needed to minimise HEN changes and thus HEN retrofit cost.

\section{Acknowledgement}

The authors gratefully acknowledge the Mexican National Council of Science and Technology (CONACyT) and the Roberto Rocca Education Program (RREP) for their financial support of PhD studies at the University of Manchester.

\section{References}

Aspen-HYSYS, 2012, Software, Version 7.3, Aspen Tech Inc, USA.

Branan, C. R., 2011, Rules of Thumb for Chemical Engineers, Burlington: Elsevier Science, Burlington.

Bravo, J. L., 1997, Select structured packings or trays?, Chemical Engineering Progress, 93, 7, 36-41.

Chen, L., 2008, Heat-integrated crude oil distillation system design, PhD Thesis, The University of Manchester, Manchester, UK.

de Oliveira Filho, L. O., Queiroz, E. M., Costa, A. L. H., 2007, A matrix approach for steady-state simulation of heat exchanger networks, Applied Thermal Engineering, 27, 14-15, 2385-2393.

Enríquez-Gutiérrez, V. M., Jobson, M., Smith, R., 2014, A design methodology for retrofit of crude oil distillation systems, Computer Aided Chemical Engineering, Volume 33, 1549-1554, http://dx.doi.org/10.1016/B978-0-444-63455-9.50093$\underline{3}$.

Gadalla, M., Jobson, M., Smith, R., 2003a, Optimization of existing heat-integrated refinery distillation systems, Chemical Engineering Research and Design, 81, 1, 147-152.

Gadalla, M., Jobson, M., Smith, R., 2003b, Shortcut models for retrofit design of distillation columns, Chemical Engineering Research and Design, 81, 8, 971986.

Gadalla, M., Kamel, D., Ashour, F., din, H. N. E., 2013, A New Optimisation based Retrofit Approach for Revamping an Egyptian Crude Oil Distillation Unit, Energy Procedia, 36, 0, 454-464, http://dx.doi.org/10.1016/j.egypro.2013.07.051.

Green, D. W., Perry, R. H., 2007, Perry's Chemical Engineers' Handbook, McGrawHill Professional, New York, USA.

Kencse, H., Manczinger, J., Szitkai, Z., Mizsey, P., 2007, Retrofit design of an energy integrated distillation system, Periodica Polytechnica: Chemical Engineering, 51, 1, 11-16.

KG-Tower, 2012, software, version 5.1, Koch-Glitsch LP, USA.

Kister, H. Z., 1992, Distillation design McGraw-Hill, Boston, USA.

Kister, H. Z., Gill, D. R., 1992, Flooding and pressure drop prediction for structured packings, IChemE Symp. Ser, 128, A109-A123. 
Kister, H. Z., Scherffius, J., Afshar, K., Abkar, E., 2007, Realistically predict capacity and pressure drop for packed columns, Chemical Engineering Progress, 103, 7, 28-38.

Koch-Glitsch, 2006, Introduction to KG-Tower: Tray\& Packed Tower Sizing Software Program, Version 2.0 [Online]: Koch-Glitsch, L.P., Available: http://www.nt.ntnu.no/users/skoge/prost/proceedings/distillation10/DA2010\%2 0Sponsor\%20Information/Koch\%20Glitsch/KGTower/IntroKGTowerV2.0.pdf [Accessed October 2014].

Koch-Glitsch, 2013, Glitsch Ballast Tray Design Manual: Bulletin No. 4900 [Online]: Koch-Glitsch, L.P., Available: http://www.kochglitsch.com/Document\%20Library/Bulletin-4900.pdf [Accessed October 2014].

Liu, Z. Y., Jobson, M., 2004, Retrofit design for increasing the processing capacity of distillation columns: 1. A Hydraulic performance indicator, Chemical Engineering Research and Design, 82, 1, 3-9.

Ochoa-Estopier, L. M., Jobson, M., Chen, L., Rodríguez, C., Smith, R., 2014, Optimisation of heat-integrated crude oil distillation systems. Part I: The distillation model, Industrial and Engineering Chemistry Research, [Under review].

Ochoa-Estopier, L. M., Jobson, M., Smith, R., 2013, Retrofit of heat exchanger networks for optimising crude oil distillation operation, Chemical Engineering Transactions, 35, 133-138, 10.3303/CET1335022.

Resetarits, M. R., 2010, Propelling distillation research, Chemical Engineering, 117, 6, 26-27.

Resetarits, M. R., 2014, Chapter 2 - Distillation Trays, In: Olujić, A. G., ed. Distillation: Equipment and Processes, Academic Press, Boston, 35-84.

Shahabinejad, H., Feghhi, S. A. H., Khorsandi, M., 2014, Structural inspection and troubleshooting analysis of a lab-scale distillation column using gamma scanning technique in comparison with Monte Carlo simulations, Measurement, 55, 375-381, http://dx.doi.org/10.1016/j.measurement.2014.03.015.

Smith, R., 2005, Chemical Process Design and Integration, John Wiley \& Sons, Ltd., Chichester, UK.

Smith, R., Jobson, M., Chen, L., 2010, Recent development in the retrofit of heat exchanger networks, Applied Thermal Engineering, 30, 16, 2281-2289.

Stichlmair, J., 1998, Distillation: Principles and Practice, Wiley-VCH, New York, USA.

Thernesz, A., Varga, Z., Rabi, I., Czaltig, Z., Lörincova, M., 2010, Applying process design software for capacity increase and revamp of distillation units, Clean Technologies and Environmental Policy, 12, 2, 97-103.

Uerdingen, E., Fischer, U., Hungerbühler, K., Gani, R., 2003, Screening for profitable retrofit options of chemical processes: A new method, AIChE Journal, 49, 9, 2400-2418.

Vatavuk, W. M., 2002, Updating the CE plant cost index, Chemical Engineering, 109, 1, 62-70.

Watkins, R. N., 1979, Petroleum refinery distillation, Gulf Pub. Co., Book Division, Houston, USA.

Wei, Z. Q., Zhang, B. J., Wu, S. Y., Chen, Q. L., Hui, C. W., 2012, A hydraulicsbased heuristic strategy for capacity expansion retrofit of distillation systems and an industrial application on a light-ends separation plant, Chemical Engineering Research and Design, 90, 10, 1527-1539. 
